\title{
Intraseasonal variability of sea level in the Western North Pacific
}

\section{Article}

Published Version

Creative Commons: Attribution-Noncommercial-No Derivative Works 4.0

Open Access

Liu, H., Feng, X. ORCID: https://orcid.org/0000-0003-4143107X, Tao, A. and Zhang, W. (2021) Intraseasonal variability of sea level in the Western North Pacific. Journal of Geophysical Research - Oceans, 126 (6). e2021JC017237. ISSN 0148-0227 doi: https://doi.org/10.1029/2021JC017237 Available at https://centaur.reading.ac.uk/98151/

It is advisable to refer to the publisher's version if you intend to cite from the work. See Guidance on citing.

To link to this article DOI: http://dx.doi.org/10.1029/2021JC017237

Publisher: American Geophysical Union

All outputs in CentAUR are protected by Intellectual Property Rights law, including copyright law. Copyright and IPR is retained by the creators or other copyright holders. Terms and conditions for use of this material are defined in the End User Agreement.

\section{www.reading.ac.uk/centaur}

\section{CentAUR}

Central Archive at the University of Reading 
Reading's research outputs online 


\section{JGR Oceans}

\section{RESEARCH ARTICLE \\ 10.1029/2021JC017237 \\ Key Points: \\ - Madden-Julian Oscillation (MJO) strongly affects intraseasonal variation of sea level over the Western North Pacific (WNP) in winter, with the largest effects in the tropics \\ - Boreal Summer Intraseasonal Oscillation (BSISO) has significant effects on sea level over the WNP in summer, with the strongest impacts in the subtropics of WNP \\ - MJO and BSISO can largely alter the occurrence of extreme sea level events}

Supporting Information: Supporting Information may be found in the online version of this article.

Correspondence to:

A. Tao,

aftao@hhu.edu.cn

Citation:

Liu, H., Feng, X., Tao, A., \& Zhang, W. (2021). Intraseasonal variability of sea level in the Western North Pacific. Journal of Geophysical Research: Oceans, 126, e2021JC017237. https:// doi.org/10.1029/2021JC017237

Received 3 FEB 2021 Accepted 18 MAY 2021

\section{Intraseasonal Variability of Sea Level in the Western North Pacific}

\author{
Haolang Liu ${ }^{1,2}$ (1) , Xiangbo Feng ${ }^{1,3}$ (D), Aifeng Tao ${ }^{2}$ (), and Wei Zhang ${ }^{1,2}$ \\ ${ }^{1}$ State Key Laboratory of Hydrology-Water Resources and Hydraulic Engineering, Hohai University, Nanjing, China, \\ ${ }^{2}$ College of Harbor, Coastal and Offshore Engineering, Hohai University, Nanjing, China, ${ }^{3}$ National Centre for \\ Atmospheric Science and Department of Meteorology, University of Reading, Reading, UK
}

Abstract Sea levels in the Western North Pacific (WNP) are presented with anomalous intraseasonal variations. This study examines the response of sea level in the WNP to the atmospheric Intraseasonal Oscillation modes, namely the Madden-Julian Oscillation (MJO) and the Boreal Summer Intraseasonal Oscillation (BSISO), using the 25 years (1993-2017) of satellite altimetry and barotropic model output. In winter, the MJO has significant effects on the component of sea level due to the instant wind and atmospheric pressure effects (high-frequency), showing an eastward propagation pattern in most regions, with the strongest effects in the western marginal seas. The MJO-associated pattern of dynamical (lowfrequency) component of sea level propagates southward, with the significant effects mostly in the tropics. In summer, the BSISO-associated pattern of the high-frequency component of sea level moves from southwest to northeast, with the largest anomalies in the middle of WNP $\left(20^{\circ} \mathrm{N}-30^{\circ} \mathrm{N}\right)$, while the strongest BSISO effects on the low-frequency component are detectable mostly in the coasts of China and east of the Philippines. The MJO and BSISO can also modulate the probability of extreme sea level events. In winter, during phases 2-5, MJO increases the chance of extreme high events in the high-frequency component of sea level by $100 \%-200 \%$ in the western coasts and the tropics. In summer, in BSISO phases 6-7, the chance of extreme high events in the high-frequency component of sea level is enhanced by $>300 \%$ in the South China Sea and east of the Philippines.

Plain Language Summary The coastal regions of the Western North Pacific (WNP) are densely populated areas, which are exposed to tremendous oceanic hazards. The intraseasonal variability of sea level may alter the occurrence of extreme sea level events when superimposing on other factors under extreme conditions. Thus, understanding the variations of sea level in the WNP on intraseasonal timescales is helpful for marine disaster prevention and mitigation. The atmospheric Intraseasonal Oscillation (ISO) is one of the dominant modes of climate variability on intraseasonal timescales, including the Madden-Julian Oscillation (MJO) and the Boreal Summer Intraseasonal Oscillation (BSISO). In this study, we investigate the relationship between the atmospheric ISO and WNP sea level over the satellite era (1993-2017) using observational data. Our analysis suggests that the atmospheric ISO significantly modulates the intraseasonal variations of WNP sea level both in winter and summer seasons, including the probability of extreme sea level events, through altering the convection and surface wind circulations associated with, or originated from, the atmospheric ISO. These findings imply the potential for developing a statistical approach to predict the intraseasonal variability of sea level extremes.

\section{Introduction}

Atmospheric and oceanic phenomena can vary on intraseasonal timescales. Intraseasonal variability provides a bridge between weather variability, which usually occurs on timescales of a few days, and seasonal variability, which occurs with a period of $>60$ days. Understanding these intraseasonal variations is of great interest to research and forecast communities as this may help to develop and improve the skills in predicting oceanic and atmospheric fields a few weeks ahead. The intraseasonal variability of sea level can have a crucial impact on the coastal flooding risk as it may alter the occurrence of extreme sea level events when superimposing on other factors under extreme conditions.

The Intraseasonal Oscillation (ISO) is one of the dominant modes of climate variability especially in the tropics. It has significant seasonality in frequency, intensity, location, and propagation (Hartmann et al., 1992; 
Madden, 1986; B. Wang \& Rui, 1989). In boreal winter (December-February), the Madden-Julian Oscillation (MJO; Madden \& Julian, 1971, 1972) is known as the dominant mode of intraseasonal variability in the tropical atmosphere, and it is quasi-periodic on timescales of 30-90 days (Wheeler \& Hendon, 2004; Zhang, 2005). The MJO normally originates in the tropical Indian Ocean and then propagates eastward along the equator. After the Maritime Continent, it starts weakening but continues to travel eastward before finally dissipating in the Western Hemisphere. MJO is associated with planetary-scale convections, which could have a strong impact on extreme rainfall in the tropics (e.g., Anandh \& Vissa, 2020; Xavier et al., 2014). In boreal summer (June-August), the Boreal Summer Intraseasonal Oscillation (BSISO) is the prevailing ISO mode in the tropics (J.-Y. Lee et al., 2013; B. Wang \& Xie, 1997), for which the large-scale circulation, and propagation could be more complicated than the MJO. Apart from an eastward movement of related convections in the tropics, the BSISO is also featured with an additional northward propagation. The BSISO consists of two major modes, the 30-60-day and the 10-20-day oscillations (Kikuchi et al., 2012; J.-Y. Lee et al., 2013). The 30-60-day oscillation is the dominant mode, featured with prominent northeastward propagation (B. Wang \& Xie, 1997), while the 10-20-day mode is weaker and mainly progressing northwestward (J.-Y. Lee et al., 2013).

The ISO of the atmosphere can significantly influence the ocean. Due to the strong modulations on heavy rainfall (e.g., Anandh \& Vissa, 2020; P. Ren et al., 2018; Xavier et al., 2014) and tropical cyclones (e.g., Hall et al., 2001; Maloney \& Hartmann, 2000a, 2000b), the atmospheric ISO can reduce the sea surface temperature after a few days of lag (e.g., Feng, Haines, \& de Boisséson, 2018; Feng, Haines, Liu, et al., 2018; Roxy \& Tanimoto, 2012; Shinoda et al., 1998; Woolnough et al., 2000). Relatedly, Han et al. (2001), Iskandar et al. (2005), and Nagura and McPhaden (2012) found a robust relationship between the atmospheric ISO and the Indian Ocean circulation. By analyzing the tide gauge records and satellite altimetry, studies also suggested that the MJO activities can affect sea level variability in some marginal seas, including the west coast of the American continent, the Gulf of Carpentaria, and the northeastern part of the Indian Ocean (Oliver \& Thompson, 2010, 2011). In the Gulf of Carpentaria, the MJO could be responsible for sea level variations up to $6 \mathrm{~cm}$ (Oliver \& Thompson, 2011). The MJO-related surface wind was thought to be responsible for the observed MJO-sea level relationships (Oliver, 2014). Note that in Oliver and Thompson $(2010,2011)$ and Oliver (2014), the inverted barometer (IB) effect was removed from the analyzed sea level data. Sea level isostatically reacts to the atmospheric pressure loading on the sea surface by the inverted barometer (IB) effect $\left(\eta_{I B}\right)$ in the open ocean (Feng, Tsimplis, Marcos, et al., 2015; Feng, Tsimplis, \& Woodworth, 2015; Ponte, 2006; Wunsch \& Stammer, 1997). The IB effect can be written as $\eta_{I B}=-1 / \rho g\left(P-P_{r e f}\right)$, where $\rho$ and $g$ are the water density and gravity acceleration, respectively, and $P-P_{r e f}$ is the fluctuation of sea level pressure $P$ relative to a long-term average $P_{\text {ref }}$ over the global ocean (Ponte, 2006; Wunsch \& Stammer, 1997). For simplicity, the consequence of a $1 \mathrm{mbar}$ increase in surface pressure is approximately $1 \mathrm{~cm}$ reduction of sea level. Although one may expect a robust relationship between IB effect and MJO, the response of sea level to MJO due to the IB effect has not been reported. In addition, as far as we know, no studies have evaluated the effects of BSISO on sea level variability in the summer season, when the tropics-originated weather systems (e.g., tropical cyclones) can cause oceanic hazards on the coasts of the ocean basins.

The coastal regions of the Western North Pacific (WNP) are densely populated areas, which are exposed to tremendous oceanic hazards, such as storm surge and ocean waves (e.g., Feng \& Tsimplis, 2014; Feng, Zheng, \& Yan, 2012). In the WNP, sea level variability is affected by both oceanographic (e.g., the western boundary currents) and atmospheric dynamics (e.g., the monsoon and tropical cyclones) on varying timescales. Marcos et al. (2012) identified the inter-annual variations of mean sea level in the marginal seas of WNP and associated them with the longer-term climatic variability. Feng, Tsimplis, Marcos, et al. (2015) and Feng, Tsimplis, and Woodworth (2015) explored the decadal variations and changes in sea level associated with tides. These sea level components were found to ultimately alter the occurrence of sea level extremes on the WNP coasts on timescales from seasonal to decadal (Feng \& Tsimplis, 2014). However, the intraseasonal variations of sea level in the WNP, including the variations of extreme sea level events, have not been well studied.

In this paper, we evaluate the response of sea level to the atmospheric ISO conditional on different seasons by analyzing the 25 years (1993-2017) of satellite altimetry data, with a focus on the WNP. The observed MJO and BSISO indices are used to indicate the conditions of atmospheric ISO in boreal winter and 
summer seasons, respectively. To distinguish the effects on the barotropic and baroclinic components of sea level, our analysis also includes the sea level data produced by the two-dimensional barotropic ocean model. Three questions will be addressed. First, what are the spatial features of the intraseasonal sea level variability in the WNP; second, how much of the intraseasonal variations of sea level, including the occurrence of extremes, are associated with the atmospheric ISO; and third, what are the drivers for the ISO-sea level relationships?

The paper is structured as follows. In Section 2, the data of sea levels and ISO indices are described together with the methodologies. In Section 3, the intraseasonal variations of sea levels are first diagnosed in winter and summer seasons. The MJO and BSISO are then linked to intraseasonal sea level variations. Finally, in this section, the effects of MJO and BSISO on the probability of extreme sea level events are identified. Conclusions and discussion are provided in Section 4.

\section{Data and Methodology}

\subsection{Data}

\subsubsection{Sea Level}

Our analysis is based on the daily sea level data in the WNP $\left(0^{\circ} \mathrm{N}-40^{\circ} \mathrm{N}, 90^{\circ} \mathrm{E}-140^{\circ} \mathrm{E}\right)$ during $1993-2017$. The dynamic atmospheric correction (DAC) data were used to analyze the variable sea levels forced by high-frequency (less than 20 days) atmospheric wind and pressure, and by low-frequency pressure (more than 20 days) from the static inverted barometer (IB) effect. The monthly average of DAC is equivalent to the isostatic IB effect (Pascual et al., 2008). The DAC data are produced by CLS Space Oceanography Division using the Mog2D model from Legos, with a spatial resolution of $1 / 4^{\circ} \times 1 / 4^{\circ}$ (Carrère \& Lyard, 2003), and distributed by the Archiving, Validation and Interpretation of Satellite Oceanographic data program (AVISO), with support from CNES (http://www.aviso.altimetry.fr/duacs/).

Multimission gridded satellite radar altimeter data were used to analyze the sea level anomalies (SLA), which are the sea surface heights with respect to a long-term mean profile (1993-2012). The spatial resolution of the gridded altimeter data is $1 / 4^{\circ} \times 1 / 4^{\circ}$, which permits resolving the sea level variability related to the mesoscale eddies. SLA daily gridded data for the study area over 1993-2017 were obtained from the Copernicus Climate Data Store (https://cds.climate.copernicus.eu/). Note that in the mission track for SLA products oceanic and atmospheric dynamics are routinely removed, including ocean tides, pole tide and DAC (Carrère \& Lyard, 2003). Adding DAC back to SLA will yield the total sea level (TSL).

Seasonal cycle and longer-term variability (including the linear trend) of sea level are removed from the daily data of DAC, SLA, and TSL to retain sea level anomalies on intraseasonal timescales. This is done through subtracting the daily climatology and the annual mean from the original data. The above data-processing procedures are also applied to the atmospheric data to have their intraseasonal variability.

\subsubsection{ISO Indices}

MJO indices for the period 1993-2017 were obtained from the Bureau of Meteorology of Australian Government (http://www.bom.gov.au/climate/mjo/). The strength and phase (1-8) of the MJO are defined by the real-time multivariate MJO index (RMM) developed by Wheeler and Hendon (2004). Only the RMM amplitudes $\left(\mathrm{RMM}^{2}+\mathrm{RMM} 2^{2}\right)^{1 / 2}$ greater than 1.0 are considered in our composite analysis, where RMM1 and RMM2 are the leading pair of principal components. Generally, phases 2-3 of MJO are concurrent with strong convections in the Indian Ocean, phases 4-5 in the Maritime Continent, phases 6-7 in the western Pacific and phases 8-1 in the West Hemisphere and Africa. Detailed descriptions of the RMM index computation can be seen in Wheeler and Hendon (2004).

BSISO indices were obtained from the APEC Climate Center of the Korea Meteorological Administration (https://apcc21.org/ser/moni.do?lang=en). The BSISO indices are derived from the first four multivariate empirical orthogonal functions (EOFs) of outgoing longwave radiation and 850-hPa zonal wind anomalies in the Asian summer monsoon region (J.-Y. Lee et al., 2013). BSISO indices include BSISO1 and BSISO2, which are defined by the first four principal components (PCs) of the EOF analysis. BSISO1 represents the canonical northward/northeastward propagating feature of the ISO, with a period of 30-60 days; BSISO2 
Table 1

Number of Days of Active Madden-Julian Oscillation (MJO) and Boreal Summer Intraseasonal Oscillation (BSISO) for Each Phase Over 1993-2017

\begin{tabular}{|c|c|c|c|c|c|c|c|c|c|}
\hline Phase & 1 & 2 & 3 & 4 & 5 & 6 & 7 & 8 & Total \\
\hline Days (MJO) & $90(5.98 \%)$ & $140(9.30 \%)$ & $207(13.75 \%)$ & $212(14.08 \%)$ & $215(14.28 \%)$ & $228(15.14 \%)$ & $262(17.40 \%)$ & $152(10.09 \%)$ & 1,506 \\
\hline Days (BSISO) & $160(11.36 \%)$ & $224(15.90 \%)$ & $193(13.70 \%)$ & $158(11.21 \%)$ & $175(12.42 \%)$ & $129(9.16 \%)$ & $172(12.21 \%)$ & $198(14.05 \%)$ & 1,409 \\
\hline
\end{tabular}

is primarily active during the premonsoon and monsoon-onset seasons with a relatively shorter period. In our analysis, only the BSISO1 amplitudes $\left(\mathrm{PC}^{2}+\mathrm{PC}^{2}\right)^{1 / 2}$ greater than 1.0 are considered. Phases $1-3$ of BSISO1 are concurrent with strong convections in the equatorial Indian Ocean, phases 4-5 in the Maritime Continent and the South China Sea (SCS) and phases 6-8 in the extratropical Pacific. Further details of the BSISO indices can be seen in J.-Y. Lee et al. (2013).

To interpret the ISO-sea level relationships, the 10-m height wind velocity and mean sea level pressure (MSLP) for the same period of time were also composited. The daily atmospheric data are from the European Center for Medium-Range Weather Forecasts (ECMWF) re-analysis Interim reanalysis (ERA-Interim) (Dee et al., 2011), which were also used to drive the Mog2D model for producing DAC data (Carrère \& Lyard, 2003).

\subsection{Methodologies}

The relationships between ISO indices and sea levels are evaluated by composite analysis, conditional on the phase and strength of ISO indices (J.-Y. Lee et al., 2013; Wheeler \& Hendon, 2004). MJO and BSISO indices are used for boreal winter (DJF) and summer (JJA) seasons, respectively. Over 1993-2017, there are 1,506 and 1,409 days identified for active MJO and BSISO, which are $66.76 \%$ and $61.26 \%$ of total days, respectively. The number of days for each phase of ISO is listed in Table 1. The significance of composite anomalies was tested at $95 \%$ confidence level.

The effects of ISO on extreme sea levels (ESLs) were evaluated as well. The 95th and fifth percentiles (R95 and R5) of the daily sea level distribution over 1993-2017 are defined as the thresholds for extreme high and low events. The thresholds are estimated at each grid point for winter and summer, separately. The cumulative probabilities of ESL events conditional on the ISO phases are calculated; the changes of ESL probability relative to the defined probability (0.05) represent the effect of the ISO on ESL occurrence. Following Xavier et al. (2014), this can be expressed as:

$$
\Delta P_{I S O_{i}}=\left(\frac{P_{\text {phase }_{i}}-P_{\text {all }}}{P_{\text {all }}}\right) \times 100 \%
$$

where $\Delta P_{I S O_{i}}$ is the percentage change in the probability of ESL allocated to ISO in phase $i$ (from 1 to 8); $P_{\text {phase }_{i}}$ is the cumulative probability of daily sea level exceeding the defined R95 or below R5 for the given ISO phase $i$; $P_{\text {all }}$ is the reference probability for ESL, that is, 0.05 in this study. Ideally, the minimum $\Delta P_{I S O_{i}}$ is $-100 \%$ when $P_{\text {phase }_{i}}=0$, and the maximum $\Delta P_{I S O_{i}}$ is $1900 \%$ when $P_{\text {phase }_{i}}=100 \%$.

To further analyze the regularity of sea level composite conditioning on ISO phases as described above, we fit the ISO-phased composite into an empirical harmonic function through a least squared regression:

$$
\eta(i)=\beta_{0}+A_{\text {amp }} * \cos \left(\frac{2 \pi}{8} *\left(i-A_{\text {phase }}\right)\right)
$$

where $\eta(i)$ is the regressed sea level composite in phase $i, \beta_{0}$ is the mean value, $A_{\text {amp }}$ is the regressed amplitude of harmonic signal corresponding to the regressed phase lag of $A_{\text {phase }}$. Ideally, $A_{\text {amp }}$ is half of the difference between regressed peak and trough of sea level composites, and $A_{\text {phase }}$ is the ISO phase when the regressed harmonic signal reaches its peak. For example, if the fitted sea level curve reaches the peak value 
a)

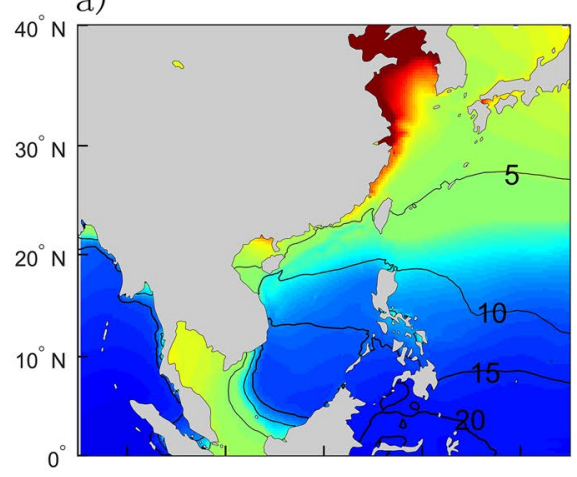

d)

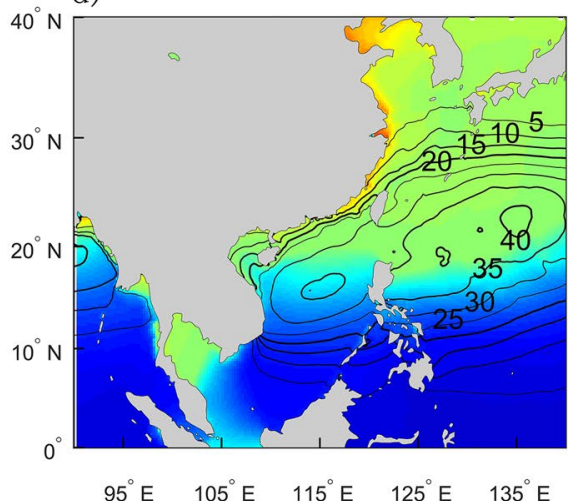

b)

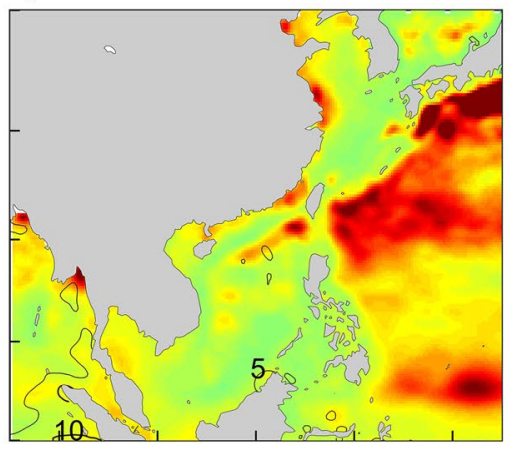

e)

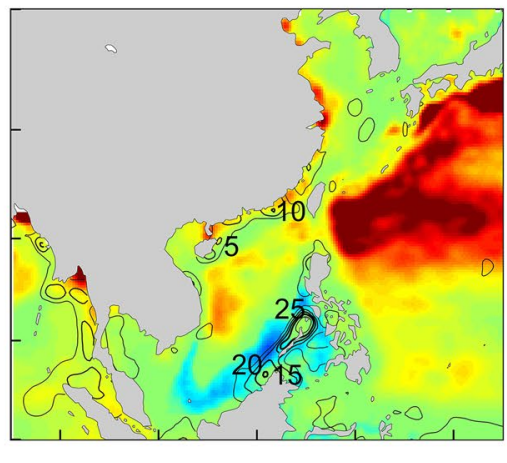

$95^{\circ} \mathrm{E} \quad 105^{\circ} \mathrm{E} \quad 115^{\circ} \mathrm{E} \quad 125^{\circ} \mathrm{E} \quad 135^{\circ} \mathrm{E}$ c)

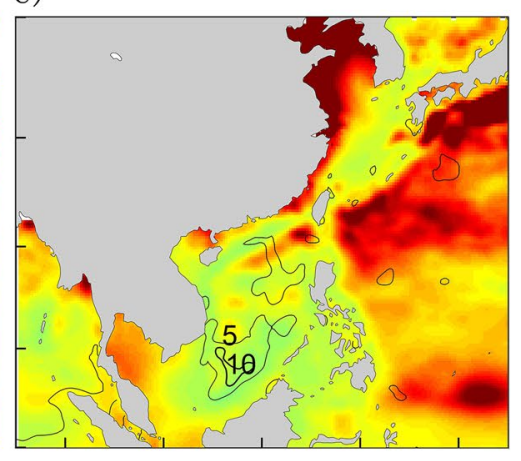

f)

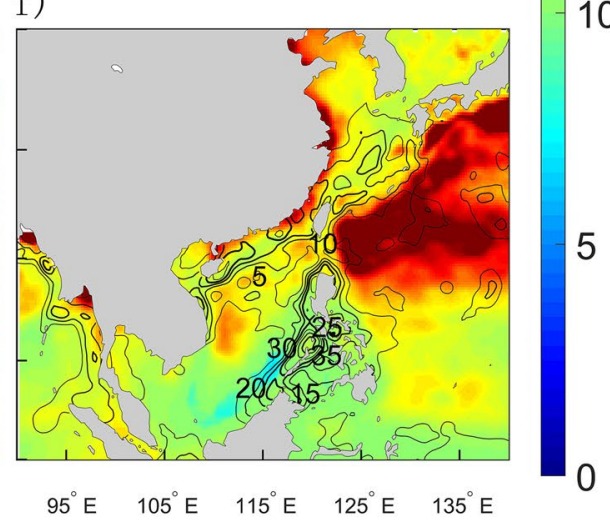

Figure 1. (a-c) Intraseasonal variance of sea level in winter, and the percentage of intraseasonal variance explained by MJO. (a-c) are for DAC, SLA, and TSL, respectively. Colors indicate the variance (units: $\mathrm{cm}^{2}$ ), and contours represent the percentage (units: \%). The contours are drawn at 5\% interval in variance explained by ISO. $(\mathrm{d}-\mathrm{f})$ as in $(\mathrm{a}-\mathrm{c})$, but for intraseasonal variance of sea level in summer, and the percentage of intraseasonal variance explained by BSISO.

of $5 \mathrm{~cm}$ in MJO Phase 2, then the $A_{\text {amp }}$ and $A_{\text {phase }}$ are estimated as $5 \mathrm{~cm}$ and 2. Note that here $A_{\text {phase }}$ values are integers, corresponding to the ISO phases 1 to 8 . The significance of the estimated harmonic parameters was tested through the student's t-test at $95 \%$ confidence level.

\section{Results}

\subsection{Intraseasonal Variance of Sea Level}

The intraseasonal variance of DAC, SLA, and TSL in winter and summer over the study period is mapped in Figure 1. For DAC, which is the sea level driven by the instantaneous atmospheric pressure and surface wind, the variance is large in the northwest and coastal regions of the basin (Figures 1a and 1d). The largest DAC variance is seen in the Yellow Sea and the Bohai Sea, with $>200 \mathrm{~cm}^{2}$ in winter and $50-100 \mathrm{~cm}^{2}$ in summer. In contrast, SLA is largely associated with oceanic dynamics, such as geostrophic currents and thermal expansion, which are not forced by the local and instantaneous atmosphere. The largest SLA variance is found in regions with strong ocean dynamics, such as in the ocean interior with energetic ocean eddies and currents (Figures $1 \mathrm{~b}$ and 1e). Large SLA variability also appears in the Luzon and Taiwan Straits where ocean currents are also strong. In the southeastern part of the SCS (around the Philippines), the SLA variability is weaker in summer than in winter. This can be caused by multiple factors related to the seasonality of ocean features. In winter, surface currents in SCS are cyclonic and strong, associated with strong northeasterly winds; in summer, the currents are anti-cyclonic and weak, associated with westerly induced by summer monsoon (Fang et al., 1998; Feng, Tsimplis, Marcos, et al., 2015; Feng, Tsimplis, \& Woodworth, 2015). In addition, in this region, the steric component of sea level fluctuations caused by the thermal expansion and salt compression is also larger in winter compared to that in summer (Feng, Tsimplis, Marcos, et al., 2015; Feng, Tsimplis, \& Woodworth, 2015). For TSL (Figures 1c and 1f), that is, the 
combination of DAC and SLA, in the open ocean, the spatial and seasonal variations of its intraseasonal variance have features similar to SLA, suggesting the dominance of ocean dynamics in the open ocean. In the northwestern and coastal regions of the basin, TSL is largely attributed to DAC, that is, the barotropic effects due to atmospheric forcing.

The percentage of intraseasonal variance explained by the atmospheric ISO is calculated by subtracting the percentage of non-ISO signals from $100 \%$ and shown in Figure 1 (contour lines). For DAC, in winter, MJO explains 5\%-20\% of the intraseasonal variance in the vast majority of regions except in the north regions and the western coastal regions, suggesting the significant effect of MJO in the tropics (Figure 1a). In contrast, in summer, $20 \%-40 \%$ of the variance at $10^{\circ} \mathrm{N}-30^{\circ} \mathrm{N}$ can be attributed to BSISO (Figure 1d). For SLA, in winter, the percentage of variance explained by the ISO is low, with $<5 \%$ in most areas; in summer, the explained percentage is $5 \%-10 \%$ in the coastal regions of China and $10 \%-25 \%$ in the southeastern part of SCS (Figures $1 \mathrm{~b}$ and 1e). The relatively high percentages in the southeastern part of SCS (Figure 1e) could be related to the surface currents driven by the alongshore wind related to BSISO. For TSL, in winter, MJO can explain $5 \%-10 \%$ of the variance around the south SCS, while in summer BSISO can capture $10 \%-30 \%$ of the variance along the coasts of China and the Philippines between $10^{\circ} \mathrm{N}$ and $30^{\circ} \mathrm{N}$ (Figures $1 \mathrm{c}$ and $1 \mathrm{f}$ ).

A large proportion of sea level intraseasonal variability is not related to MJO and BSISO. For DAC, most of the intraseasonal variance in the northern coastal regions is not related to the atmospheric ISO. The large variance might be related to the weather systems which are not originated from, or associated with, the tropical intraseasonal variability, such as the persistent winter storms and strong mid-latitude cyclones. In addition, the shallowing and coastal effects of DAC at the middle latitudes, such as in the northern China seas, can also degrade the effect of atmospheric ISO. Sea level in this shallow (mostly depth $<100 \mathrm{~m}$ ) and semi-closed region has a strong barotropic response to surface wind and pressure. The non-ISO signals can be potentially amplified by the coastal effect. For SLA, the large intraseasonal variance is mainly caused by strong ocean dynamics such as ocean currents and eddies, such as in the central SCS, in the Kuroshio region and in the ocean interior. Over these regions, ocean dynamics are not significantly influenced by instantaneous atmospheric fluctuations. Thus, the contribution explained by atmospheric ISO is usually small in the deep ocean regions. For TSL, the large intraseasonal variance appears in the northern regions, where the atmospheric ISO has limited effects on DAC, and the open ocean, where the atmospheric ISO has limited effects on SLA. As a result, a large proportion of TSL variance is not explainable to atmospheric ISO.

\subsection{Effect of Atmospheric ISO on Daily Mean Sea Level}

\subsubsection{Winter}

In boreal winter, the composite anomaly of DAC for each MJO phase is shown in Figure 2a. The overall composite values regardless of the significance test are provided in Figure S1. DAC in the WNP is significantly modulated by MJO. The effect of MJO propagates from west to east, following the movement of atmospheric convections related to MJO. In phases 2-3, MJO has the strongest impact in the western marginal seas, where the induced DAC anomalies are $2-3 \mathrm{~cm}$. With MJO propagating eastward, these positive anomalies move to the east as well. In MJO phases 7-8, negative DAC anomalies are found in the vast majority of regions, with the largest magnitude of $2-3 \mathrm{~cm}$ in the Taiwan Strait.

MSLP and surface wind velocity are composited for each phase of MJO. The anomalies of the composites are shown in Figure 3. In MJO phases 2-3, there is a large-scale low-pressure system with convergent surface wind in the western part of SCS. In contrast, in phases 7-8, a high-pressure system with divergent wind is located in the SCS. Thus, MJO-related DAC anomalies are consistent with the atmospheric forcing (Figure 2a). To further understand the relative contributions of surface wind and MSLP to the MJO-related DAC anomalies, the isostatic IB effect was subtracted from composited DAC (Figure S2). After removing the IB effect, the MJO-related anomalies of DAC are largely reduced in most regions. Surface wind only has strong impact on DAC in the coastal regions of China and the Gulf of Thailand.

Figure $2 \mathrm{~b}$ shows the composite anomaly of SLA for each phase of MJO. MJO-related SLA has an amplitude of 2-6 cm, with larger values in the tropics $\left(0^{\circ} \mathrm{N}-15^{\circ} \mathrm{N}\right)$. A distinct feature in MJO-related SLA is the large spatial variability, e.g., along the western boundary currents and in the regions with rich eddies. During MJO phases 1-2, positive SLA anomalies appear in the subtropics, while negative anomalies are found in 

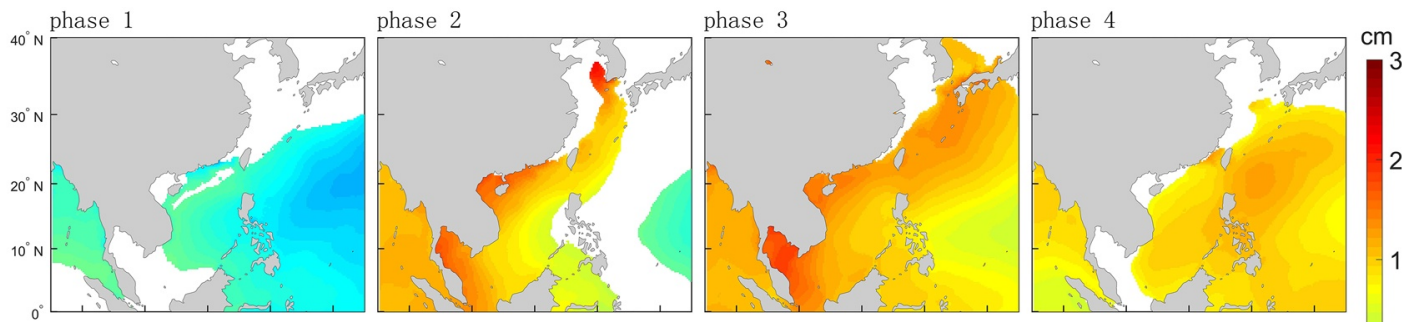

a)
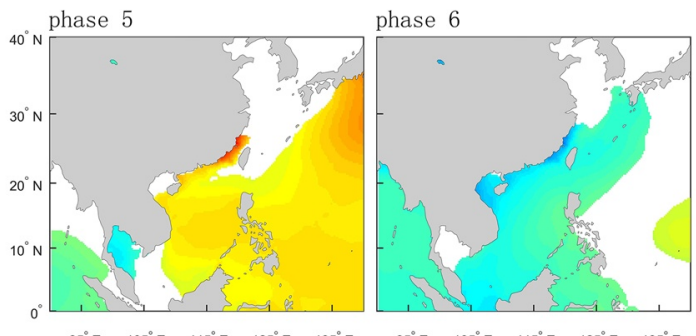

phase 7
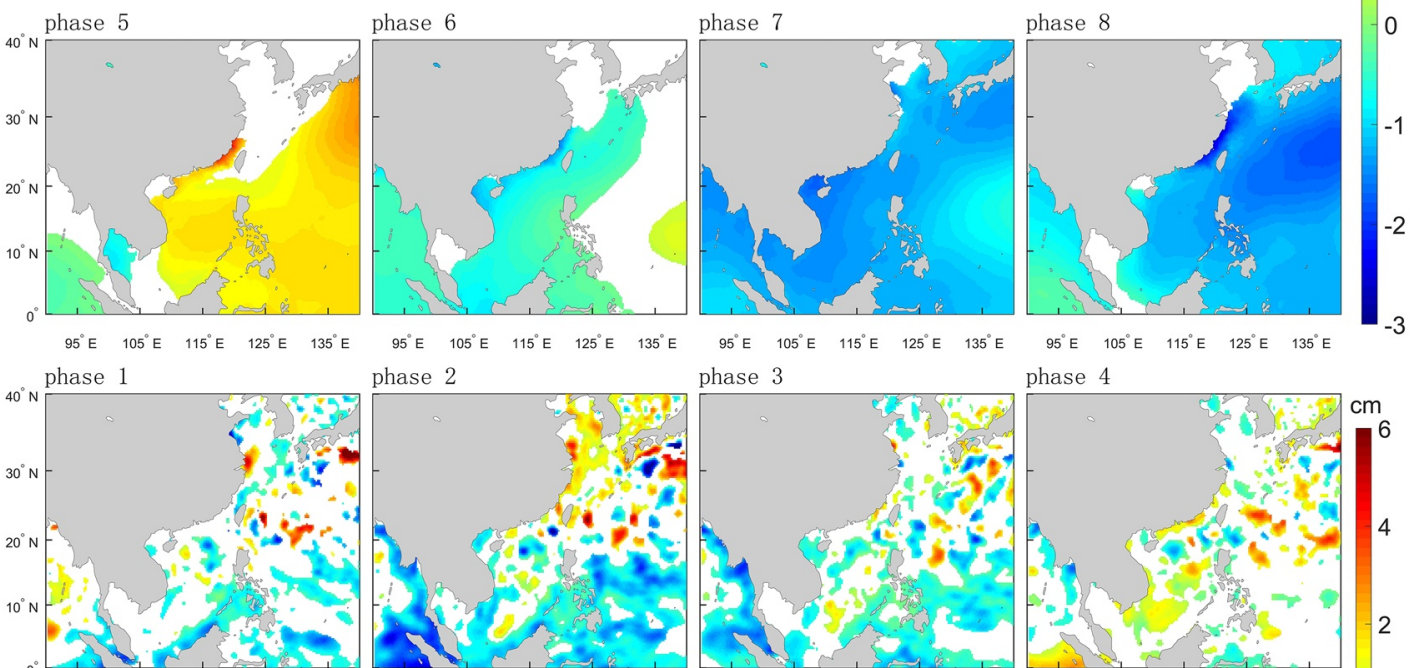
phase 3

phase 4

b)
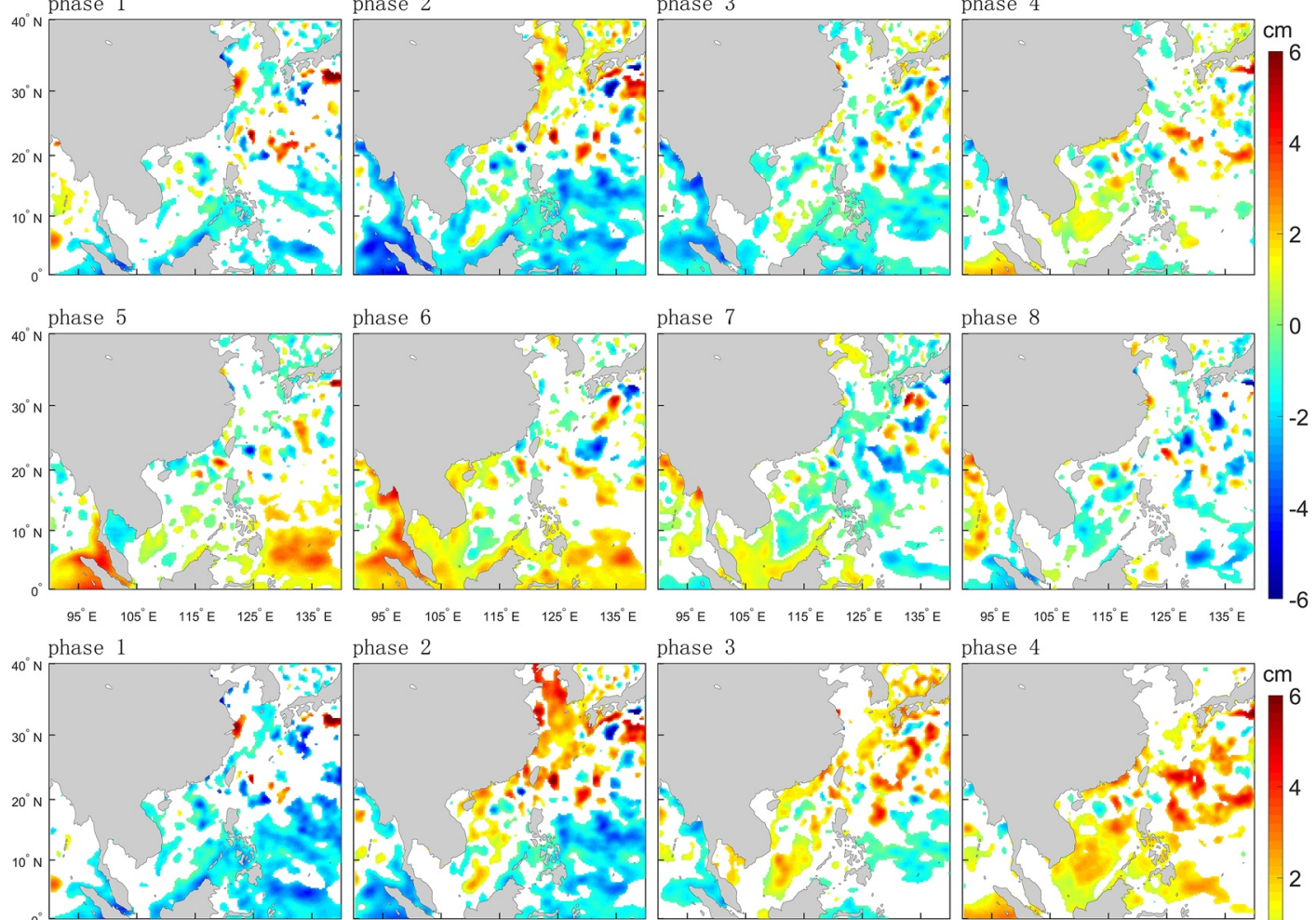
hase 3

phase 4
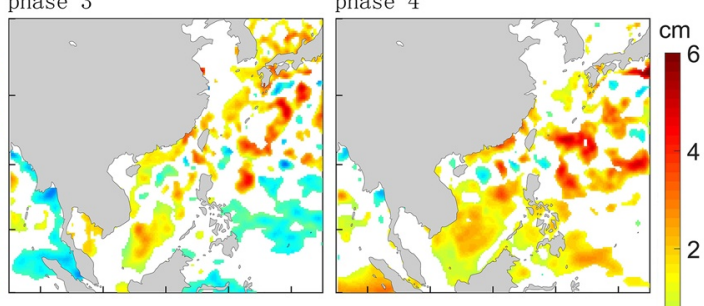

c)
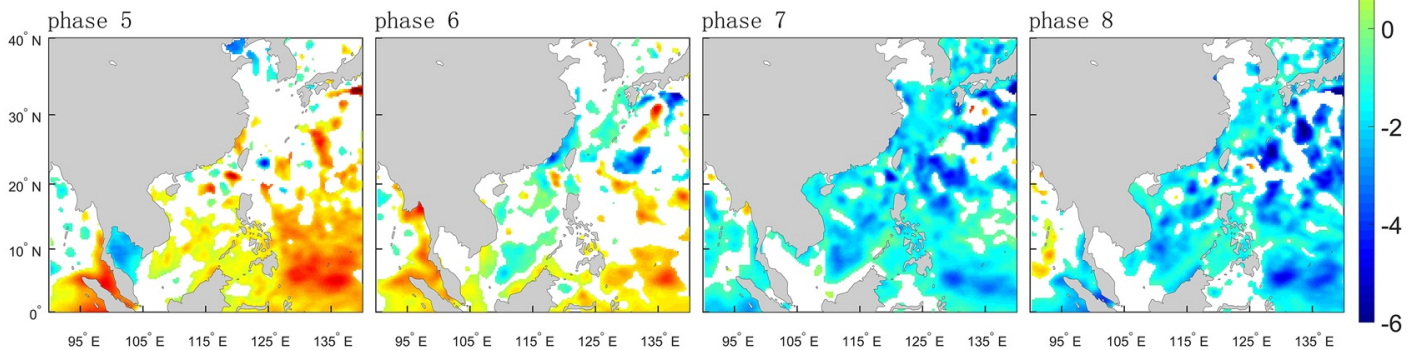

Figure 2. Composite anomalies of (a) DAC, (b) SLA, and (c) TSL in MJO phases, respectively. Blank areas indicate the composite anomalies that are not passing the significance test at 95\% confidence level. The results including insignificant composite anomalies are shown in Figure S1. 

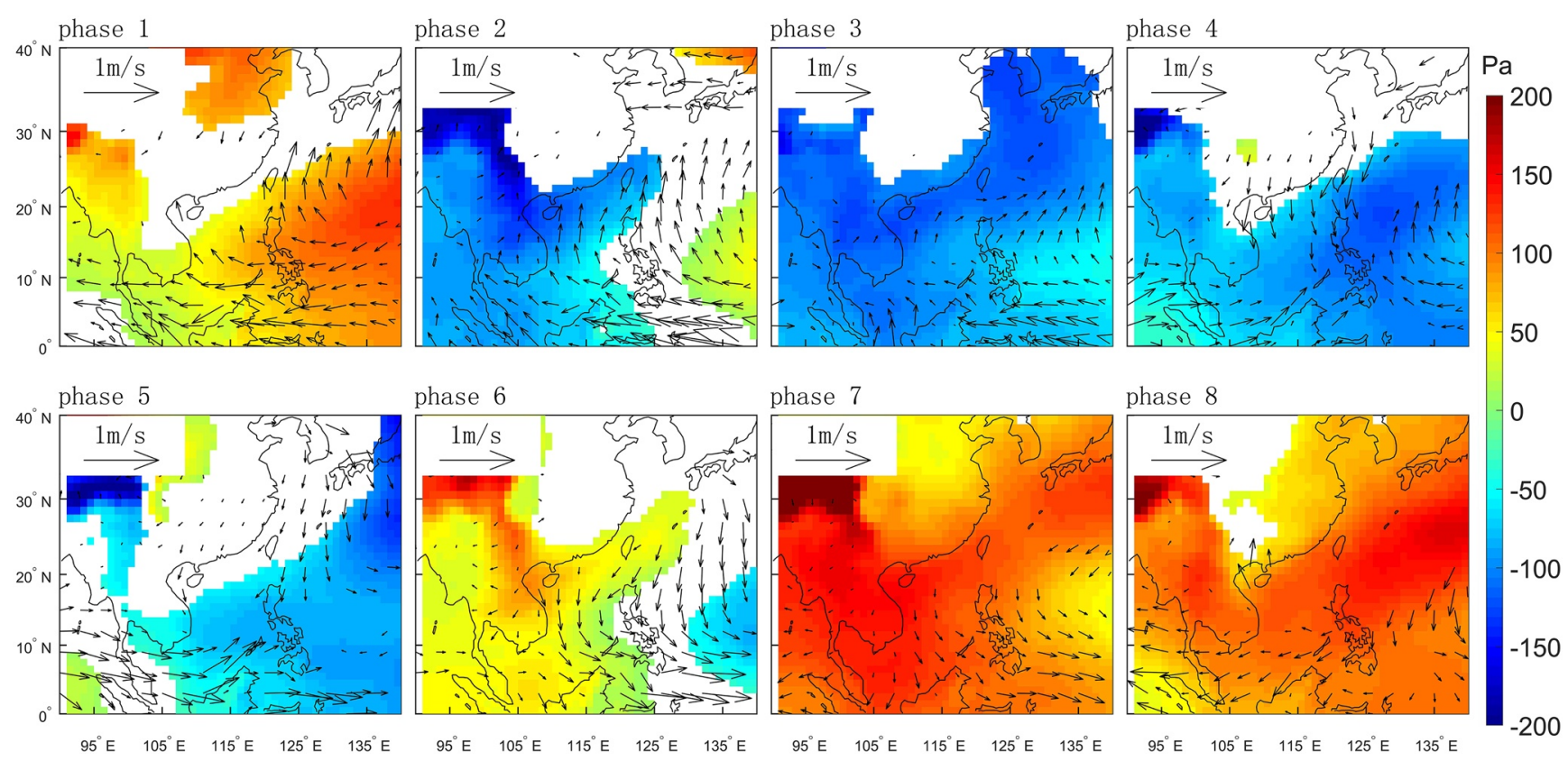

Figure 3. Composite anomalies of mean sea level pressure (MSLP) and surface wind in MJO phases, in winter. Colors indicate the MSLP (unit: Pa) and arrows represent the surface wind (unit: $\mathrm{m} / \mathrm{s}$ ). Blank areas indicate the composite anomalies that are not passing the significance test at $95 \%$ confidence level.

the tropics. In contrast, in MJO phases 5-6, positive anomalies appear in the tropics and negative values are prone to appear in the subtropics. The large-scale patterns in composites of SLA can be explained in part by the surface wind anomalies (Figure 3). In MJO phases 1-2, the anti-cyclonic wind anomaly in the southern and western WNP, accompanied with a high-pressure to the right, could drive local geostrophic currents, leading to an increase of SLA toward the East China Sea (ECS) and Sea of Japan. In the tropics, related to the easterly wind, water is divergent in the Andaman Sea and Malaysia Strait, causing the largest reduction of SLA (4-6 cm). In MJO phases 5-6, when MJO-related convections are in the basin, there is cyclonic wind anomaly. This causes seawater convergence and the eastward geostrophic currents in the tropics, which all increase SLA; conversely, SLA in the subtropics tends to reduce. In all, the response of SLA to ISO-related atmospheric forcing is less conclusive than that of DAC. This is due to the fact that SLA is mostly driven by ocean dynamics, which has no instantaneous response to atmospheric forcing on intraseasonal timescales (see our note in Section 3.1). We also analyzed the SLA composites by leading/lagging the ISO phases by a few days (not shown), as one may expect a delayed response of SLA to atmosphere. However, the results were not significantly improved.

The composite anomaly of TSL for each phase of MJO in winter is mapped in Figure 2c. As the combination of DAC and SLA, TSL exhibits a canonical northwest-southeast propagation from the coasts of China to east of the Philippines, with amplitude of 2-6 cm. In MJO phases 2-3, the largest positive TSL anomalies are found in northwestern WNP when the convection of MJO is located in the Indian Ocean. In MJO phases $7-8$, MJO tends to produce negative anomalies of TSL in the vast majority of regions, consistent with the impact on DAC.

We further fitted the MJO-allocated composite anomalies to the harmonic Equation 2 by assuming the MJO effect is anti-symmetric along the eight phases. The regressed harmonic parameters are shown in Figure 4, with values passing the significance test provided in Figure S3. Overall, the harmonic cycle of DAC regressed on MJO has an amplitude of 1-2 cm, with an eastward tilt. The largest amplitudes are found in the Taiwan Strait (Figure 4a). Figure 4a also shows the phases when the DAC anomalies reach the peak, indicating that the MJO effect distinctly propagates eastward. In the western marginal seas, the DAC anomalies peak in MJO Phase 3, when MJO-related convections are in the Indian Ocean. In the eastern WNP, the DAC anomalies peak in Phase 4, when atmospheric convections are active in the Maritime Continent. 
a)

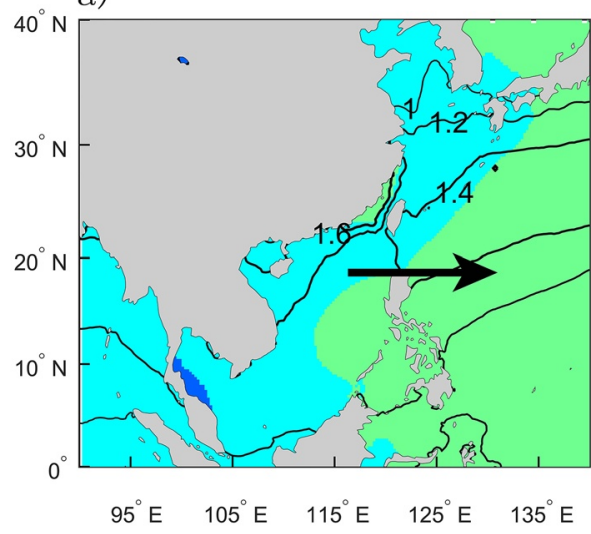

b)

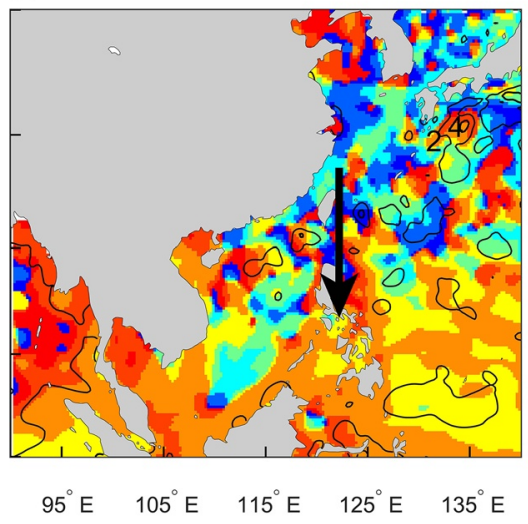

c)

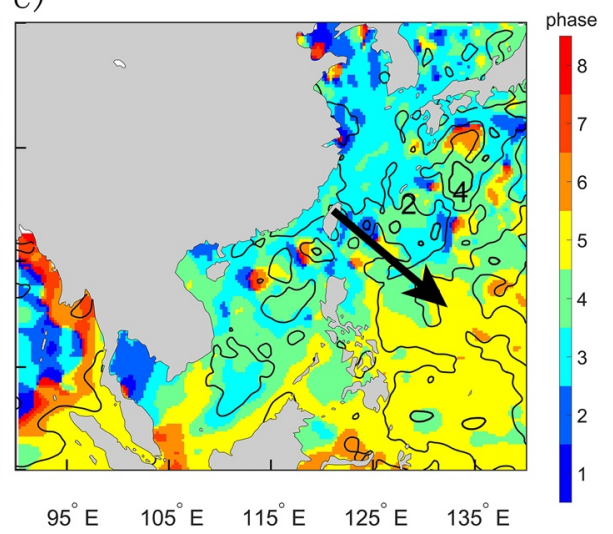

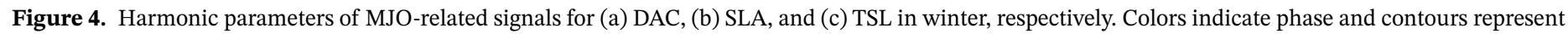

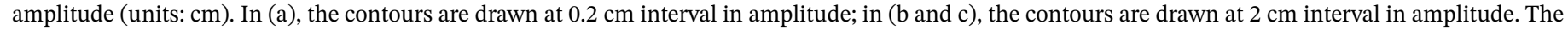
arrows indicate the direction of propagation.

For SLA, the harmonic parameters are inhomogeneous in space (Figure 4b), consistent with the composite anomalies (Figure 2b), likely related to the mesoscale ocean dynamics. We also did the harmonic analysis by delaying SLA for a few days with respect to MJO, and found that the inhomogeneous feature in Figure $4 \mathrm{~b}$ still remains (not shown). In Figure $4 \mathrm{~b}$, there is a hint that the effect of MJO on SLA is propagating southward. In the subtropics, SLA tends to peak in MJO phases 1-3, while in the tropics SLA tends to reach its maxima in MJO phases 5-7, confirming the dynamical response of SLA to MJO-related surface wind (Figure 3).

The regressed harmonic phases suggest that with MJO progressing, its effect on TSL propagates southeastward (Figure 4c). In the subtropics (e.g., the Bohai Sea and ECS), TSL anomalies reach their maxima in MJO phases 2-3; in the tropics (e.g., east of the Philippines and north of Indonesia), TSL anomalies peak in MJO phases $4-5$.

\subsubsection{Summer}

The composite anomalies of different sea level components for eight BSISO phases in boreal summer are shown in Figure 5. The overall composite values regardless of the significance test are provided in Figure S4. Intraseasonal variability in DAC is significantly modulated by BSISO in most regions of WNP except in the Gulf of Thailand, the Bohai Sea and the Sea of Japan. There is a clear southwest-northeast propagation in DAC intraseasonal anomalies (Figure 5a), from the east of Vietnam to the south of Japan. The largest effect of BSISO is located between $20^{\circ} \mathrm{N}$ and $30^{\circ} \mathrm{N}$ (east of Taiwan), with negative anomalies of $-4 \mathrm{~cm}$ in BSISO phases 3-4 and positive anomalies of $\sim 6 \mathrm{~cm}$ in BSISO phases 7-8. In the Gulf of Thailand, in phases 2, 3, 6, and 7, BSISO has a significant impact on DAC anomalies, but they are opposite to that in the central of the basin (east of Taiwan).

Composited anomalies of MSLP and surface wind velocity allocated to BSISO phases are shown in Figure 6. In the open ocean, the BSISO-related DAC anomalies can be mostly explained by MSLP. After removing the IB effect from DAC, the remaining anomalies are only significant in the western marginal seas of WNP (Figure S5), with amplitude of $\sim 2 \mathrm{~cm}$. In BSISO phases 2-3, the north-easterly wind in the tropics, accompanied with an anti-cyclonic circulation, pushes water westward to the Gulf of Thailand, resulting in $\sim 2 \mathrm{~cm}$ of DAC anomalies increase. Conversely, in BSISO phases 6-7, the south-westerly wind on the equatorial side of the cyclonic circulation pushes water away from the Gulf of Thailand, causing $2 \mathrm{~cm}$ of DAC anomalies reduction. The impact of BSISO-associated atmospheric forcing on sea level is not anti-symmetric along the eight phases, with a relatively weaker anti-cyclonic circulation in phases 3-4 and a relatively stronger cyclonic circulation in phases 7-8 (Figure 6). Consequently, the BSISO-related DAC anomalies are larger and more robust in phases $7-8$ than in phases 3-4 (Figure 5a). 

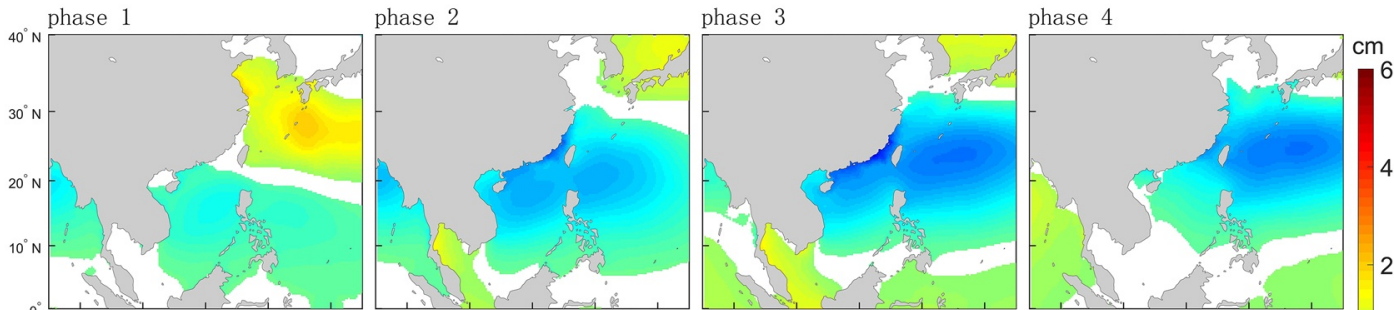

a)
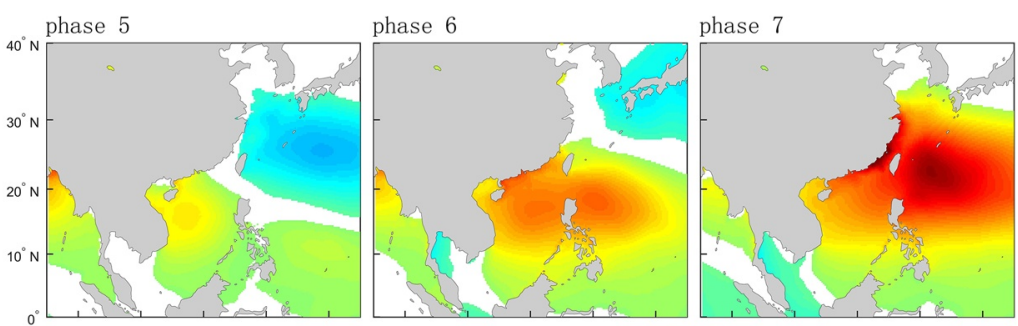

phase 8
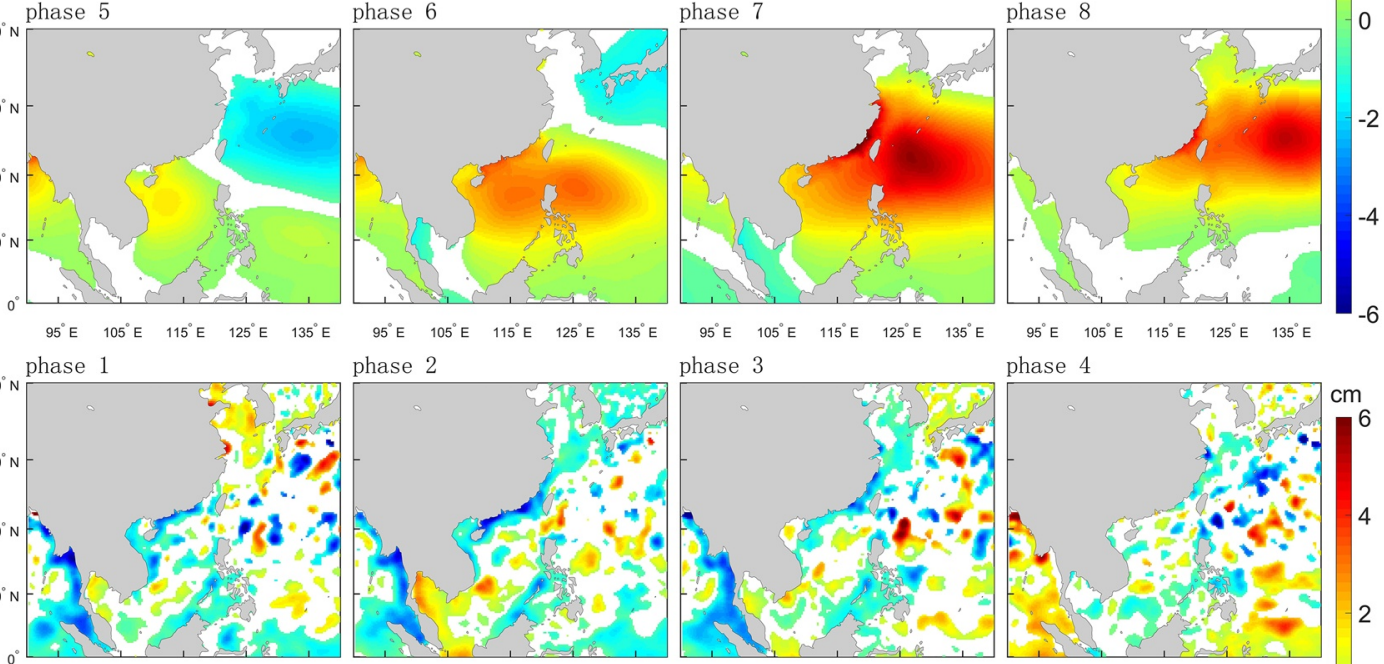
phase 2

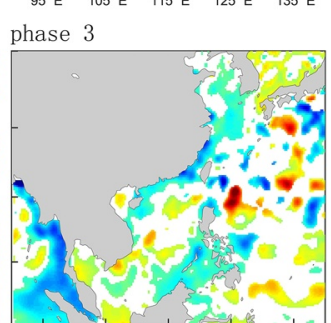

phase 4

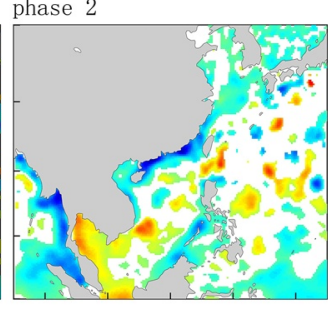

b)
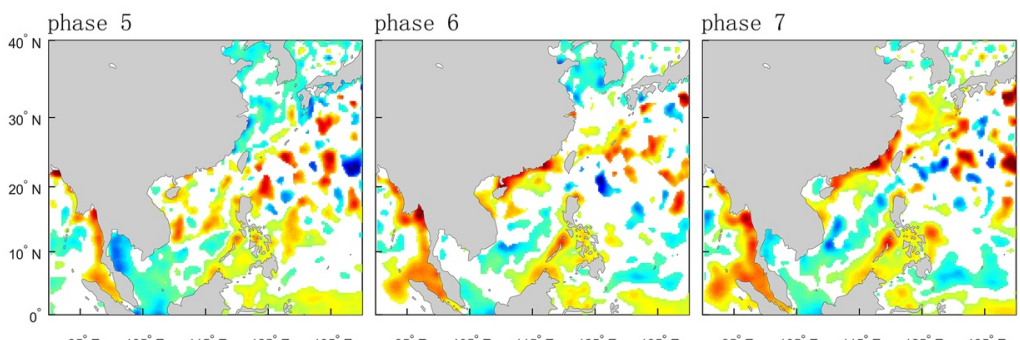

$95^{\circ} \mathrm{E} \quad 105^{\circ} \mathrm{E} \quad 115^{\circ} \mathrm{E} \quad 125^{\circ} \mathrm{E} \quad 135^{\circ} \mathrm{E}$
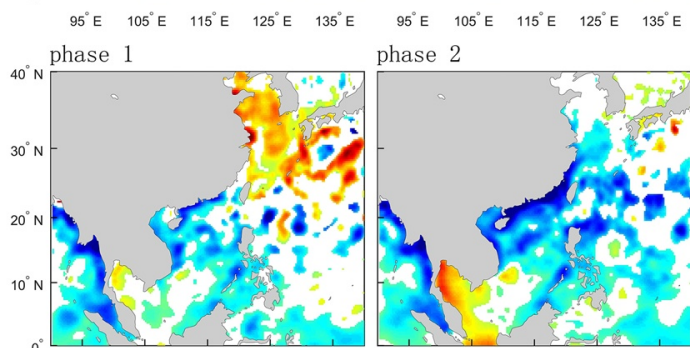
phase 2
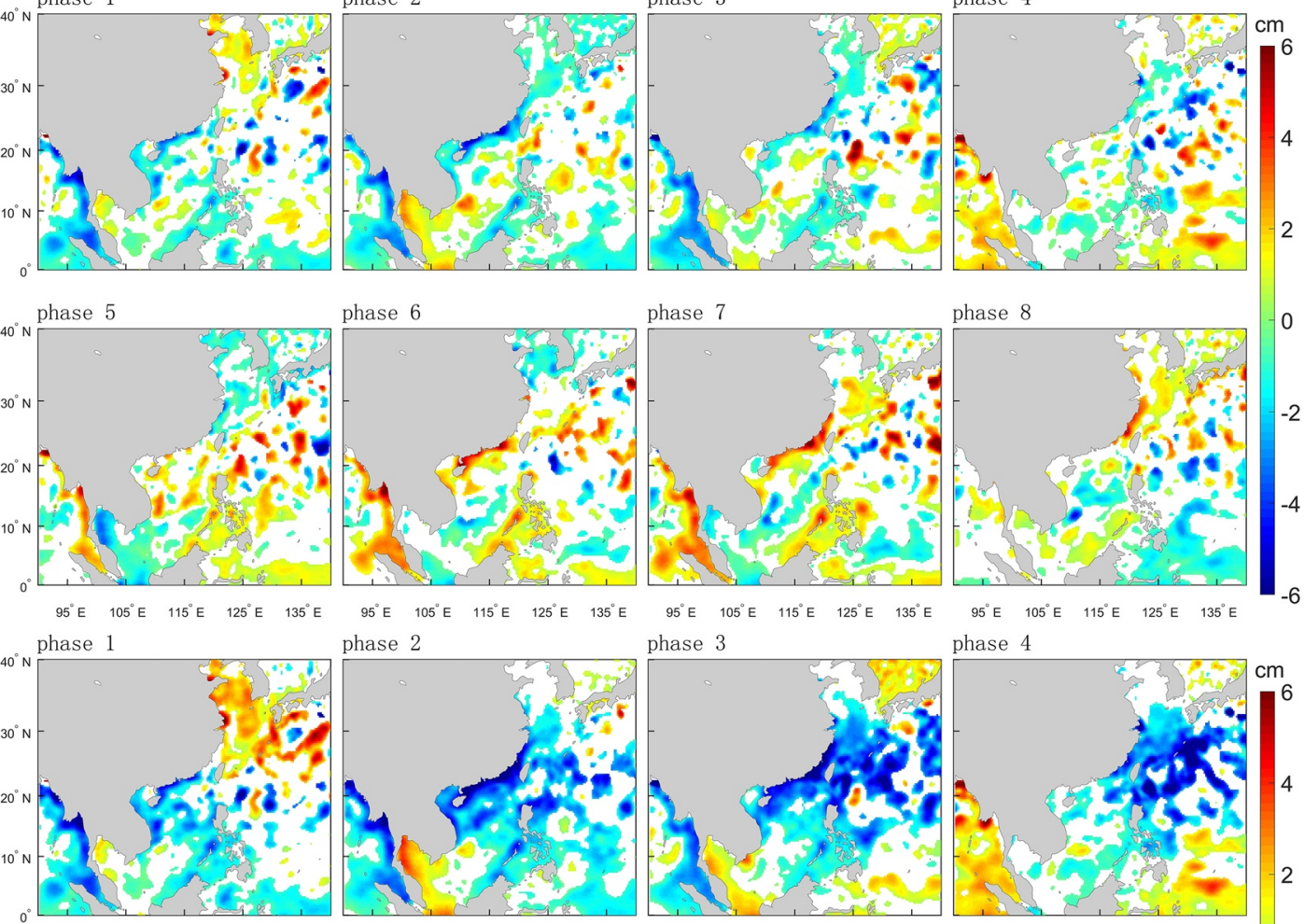

hase 4
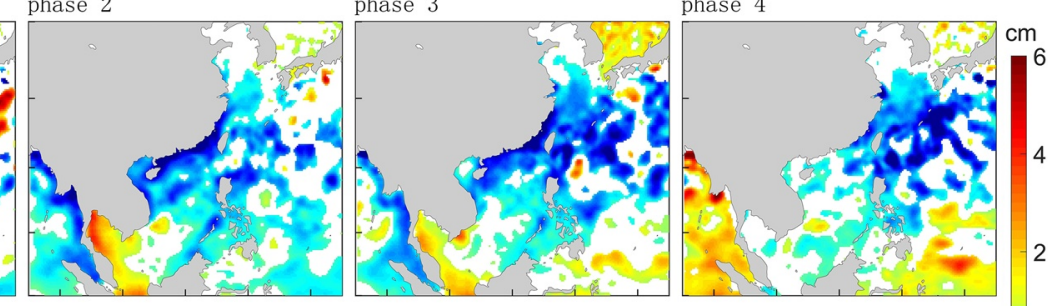

c)
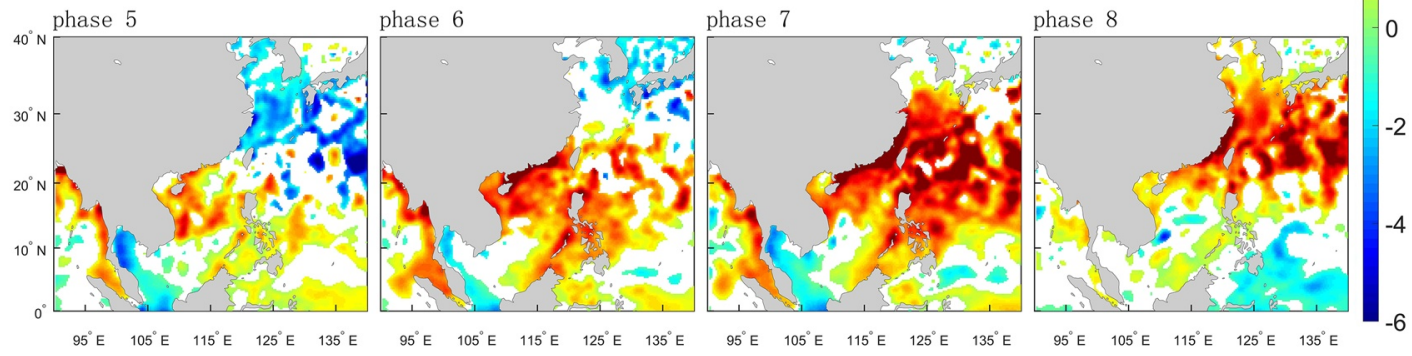

Figure 5. As in Figure 2, but for BSISO and in summer season. The results including insignificant composite anomalies are shown in Figure S4. 

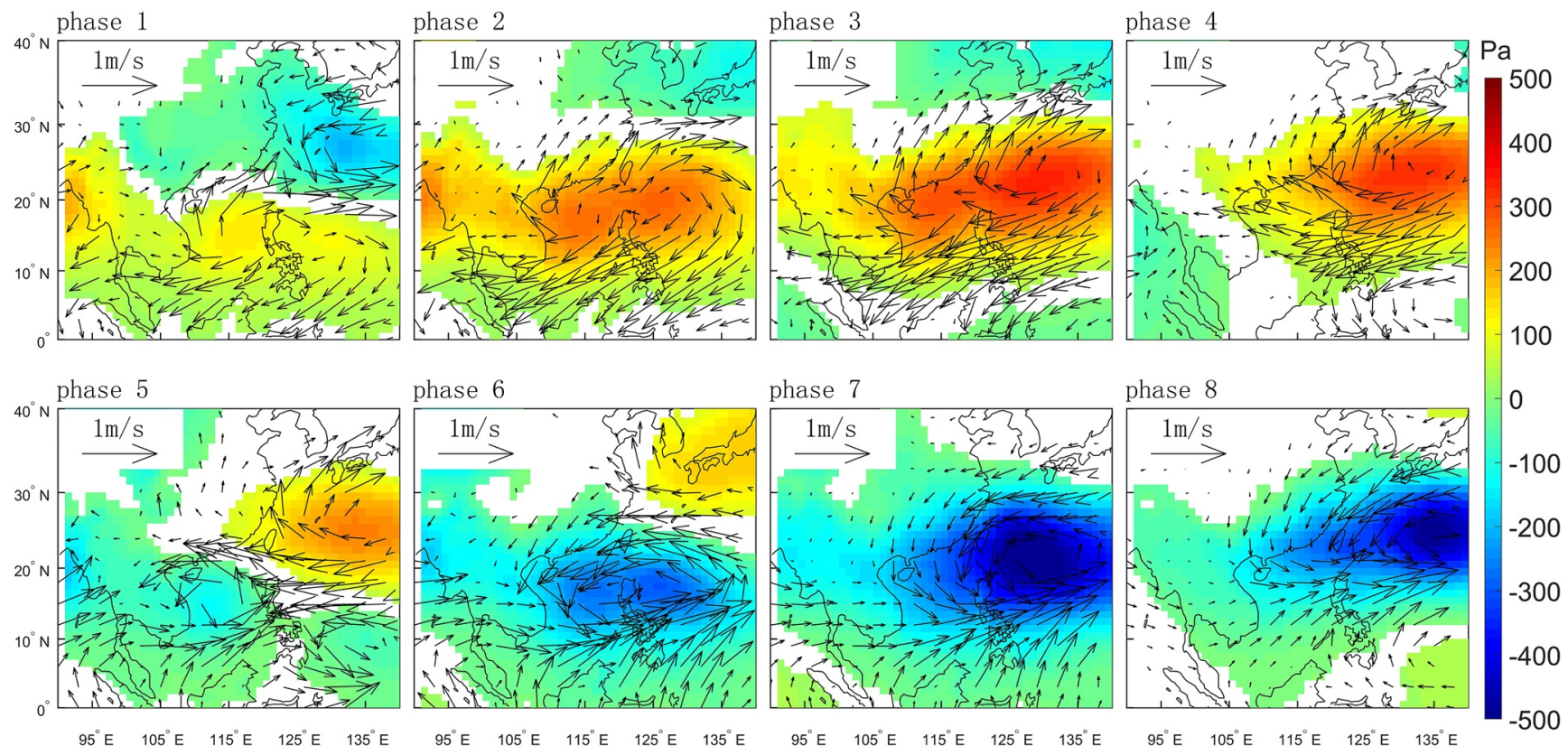

Figure 6. As in Figure 3, but for BSISO and in summer season.

The composited SLA for BSISO is shown in Figure 5b. The most pronounced effects of BSISO on SLA are found in the coastal regions and east of the Philippines, in the range of $2-6 \mathrm{~cm}$. This can be explained by the surface wind anomalies allocated to BSISO (Figure 6). The wind anomalies east of the Philippines could drive inward (outward) ocean surface currents, leading to a significant seawater convergence (divergence) in BSISO phases 1-3 (6-8). On the Chinese coasts (e.g., Taiwan Strait), the convergence (divergence) of seawater could be caused by coastal Ekman transport related to the longshore wind. Similar to the composite for MJO, the BSISO-related SLA also presents small-scale features.

The composite anomaly of TSL for each BSISO phase is shown in Figure 5c. Overall, the BSISO-related TSL has an obvious southwest-northeast propagation, during the northeastward propagation of the largescale wind circulation related to BSISO. The largest anomalies are found east of China and south of Japan, exceeding $6 \mathrm{~cm}$.

The phases of BSISO in which DAC and SLA on intraseasonal timescales reach the peak are shown in Figures $7 \mathrm{a}$ and $7 \mathrm{~b}$. Values passing the significance test are provided in Figure S6. The BSISO-related anomalies in DAC have an amplitude of $\sim 1 \mathrm{~cm}$ in the Gulf of Thailand, 1-3 cm in the SCS and east of the Philippines,

a)

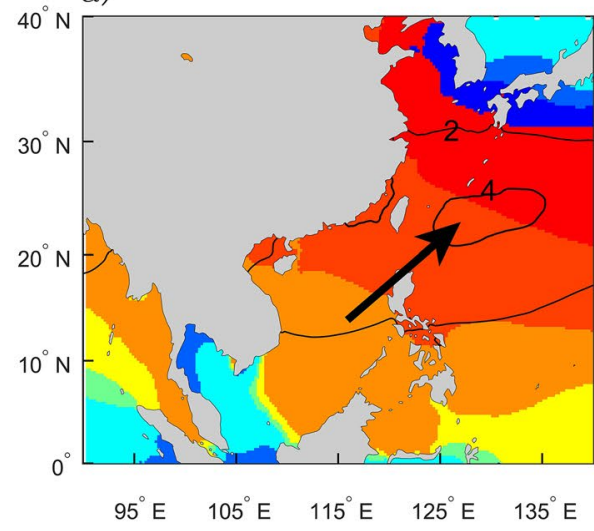

b)

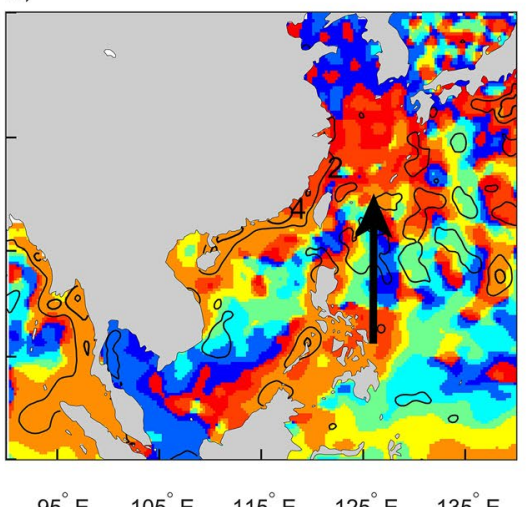

c)

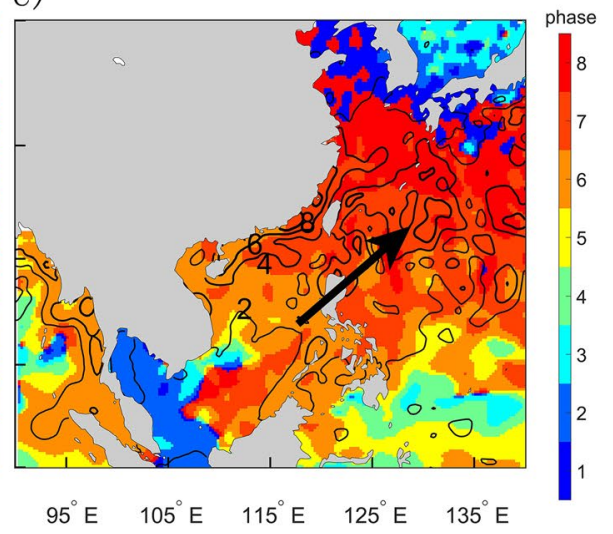

Figure 7. As in Figure 4, but for BSISO and in summer season. The contours are drawn at $2 \mathrm{~cm}$ interval in amplitude. 
and 3-4 $\mathrm{cm}$ in the ECS and south of Japan, gradually peaking in BSISO phases from 3 to 8 . Those phase changes are less homogenous in SLA, especially around the Maritime Continent, likely due to the small features of ocean dynamics (e.g., eddies and coastal wind-driven currents). The response of TSL (the combination of SLA and DAC) to BSISO is more southwest-northeast oriented. From the tropics to middle latitudes, TSL anomalies depending on BSISO are peaking in phases from 2 to 8 .

A couple of aspects need to be discussed. The first point is the weaker TSL-ISO relationship. The relationship between DAC and ISO is stronger. This difference might be due in part to the cancellations of the ISO effects on SLA and DAC. In many regions (such as SCS and east of the Philippines), DAC and SLA have different responses to atmospheric ISO in terms of phase (Figures 4 and 7). The combination of DAC and SLA can counteract the effects of atmospheric ISO on TSL.

The second point is the stronger effect of BSISO on sea level intraseasonal variability. BSISO has a stronger influence on sea level than MJO does, both in the explained percentage (Figure 1) and in the composited anomalies (Figures 2 and 5). This is associated with the fact that the BSISO-related atmospheric pressure and surface winds are stronger than those of MJO (Figures 3 and 6). Multiple factors could be responsible for the fact. First, studies show that the atmospheric ISO is significantly driven by the underlying sea surface temperature (SST) through air-sea interaction at the interface (Rajendran \& Kitoh, 2006; Sobel et al., 2008). In summer, related to the large difference between SST and lower-level atmospheric temperature, the SST forcing for atmosphere via heat flux in the tropics is strong, presented with strong atmospheric instability and strong tropical convection (Feng, Haines, \& de Boisséson, 2018; Feng, Haines, Liu, et al., 2018). In winter, the SST forcing for atmosphere is weaker in the tropics, associated with weak atmospheric instability. We thus hypothesize that the seasonal variations in the oceanic forcing may lead to a stronger ISO signal in summer than in winter. Second, the meridional gradient of SST might be another factor affecting the amplitude of ISO-related atmospheric anomaly (T. Wang et al., 2018). Since MJO propagates eastward along the equator, which is mainly a zonal movement, possibly associated in part with the zonal gradient of SST, the meridional gradient of SST may have less effect on MJO-related atmospheric anomaly. While BSISO has a south-north propagation besides the west-east propagation, its associated atmospheric anomaly could be affected by the SST gradient both zonally and meridionally, likely leading to a stronger forcing for sea level.

The third point is the possible linkage between BSISO and the western Pacific subtropical high (WPSH). For example, Hsu et al. (2017) and Huang et al. (2020) both revealed the strong modulating effect of BSISO on the north-south displacement of WPSH. In phases 2-4 (6-8), BSISO exerts anti-cyclonic (cyclonic) anomaly over SCS and east of the Philippines, which enhances (reduces) the strength of WPSH, probably through exciting a meridional propagating Rossby wave train. The enhancement (reduction) of WPSH is accompanied with a southward (northward) shift of WPSH (Hsu et al., 2017). The causal relationship between BSISO and WPSH still remains largely unknown, and sensitivity experiments using numerical models are required to address this challenge. The linkage between BSISO and WPSH suggests us a future investigation on the combined impact of WPSH and BSISO on the WNP sea levels.

\subsection{Effect of Atmospheric ISO on Extreme Sea Level}

\subsubsection{Winter}

Probability changes of extreme sea levels (ESLs) during MJO phases 1-8 are shown in Figure 8. For ESL high (R95) in winter DAC, its probability is significantly modulated by MJO, with an increase of $100 \%-200 \%$ in the western part of the basin in MJO phases 2-3 and in the southern part in phases 4-5, relative to the reference probability for ESL (Figure 8a). Reduction of $50 \%-100 \%$ of ESL high probability is seen in the same regions in MJO phases 6-7 and 8-1. The effects of MJO on ESL high are consistent with those on daily mean sea level (Figure 2a). The opposite patterns are found in ESL low (R5) (Figure 8b).

The timing of the probability changes of ESLs regressed to MJO lifecycle for each grid is shown in Figure 9, with values passing the significance test provided in Figure S7. It is seen that the MJO modulations of the probability of DAC extremes are propagating eastward, with larger regressed amplitudes in the equatorial region. For winter DAC, the amplitudes regressed to MJO lifecycle for the probability changes of the ESL high events are 50\% in the coasts of China and 100\% over the Maritime Continent; for the ESL low events, the amplitudes are up to $150 \%$ east of the Philippines. 

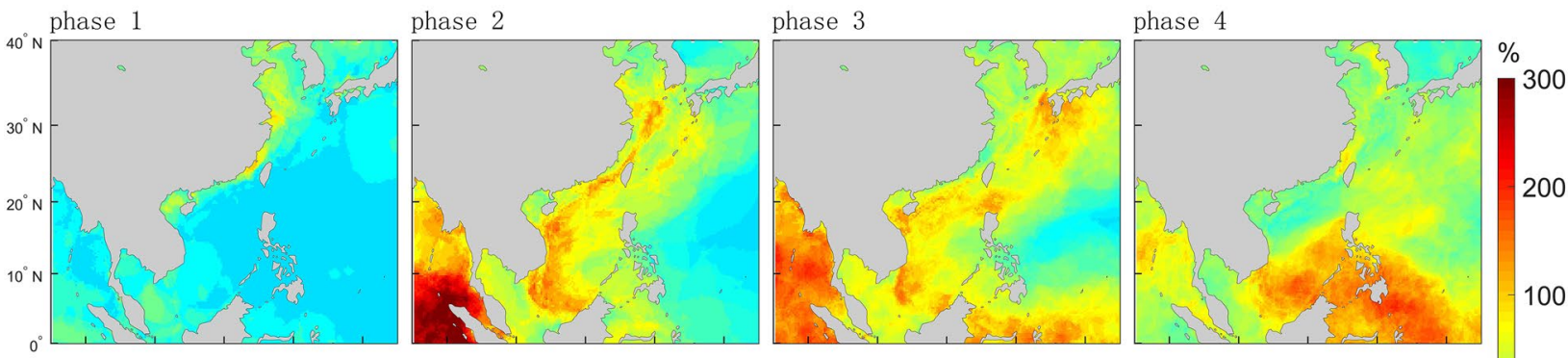

a)
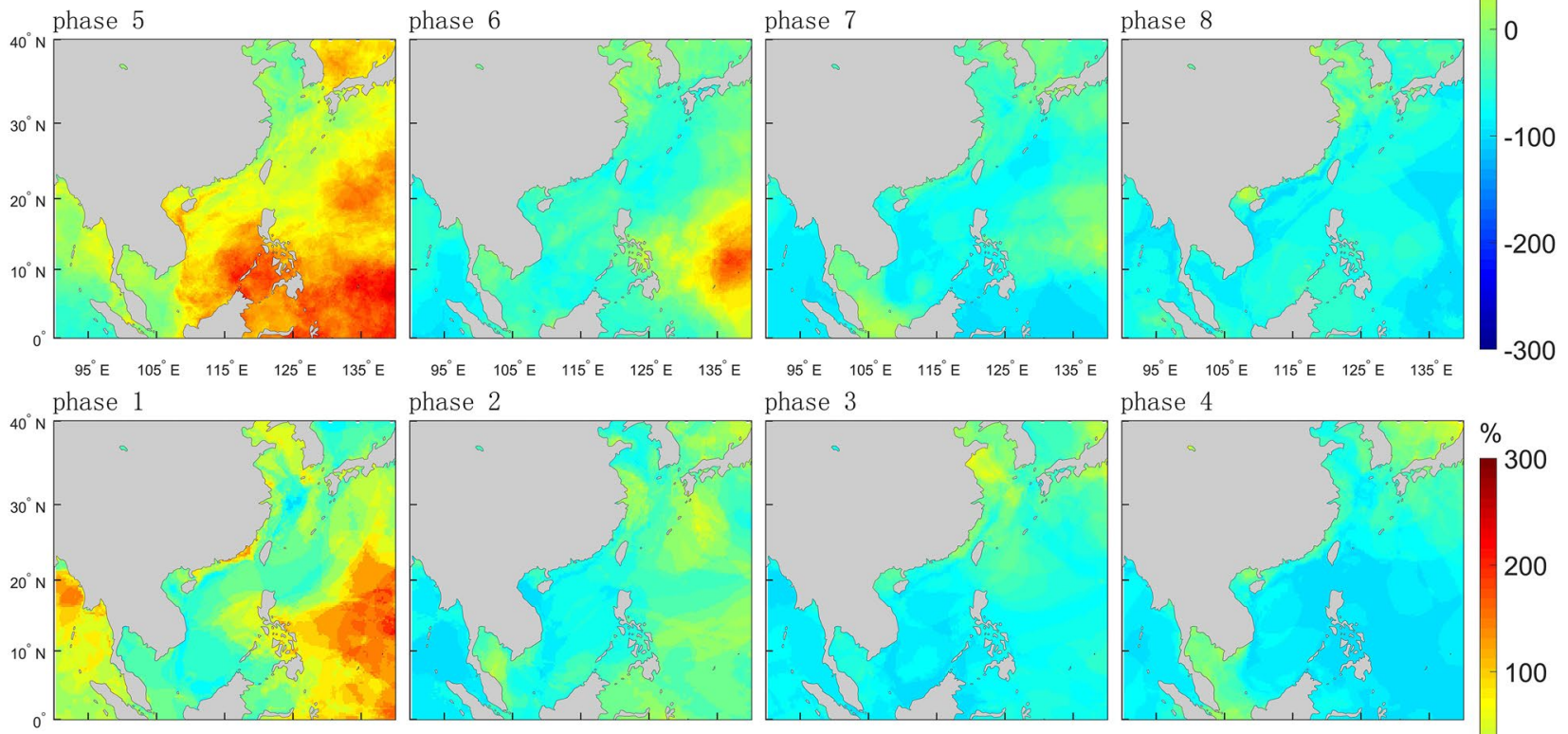

phase 2

phase 3
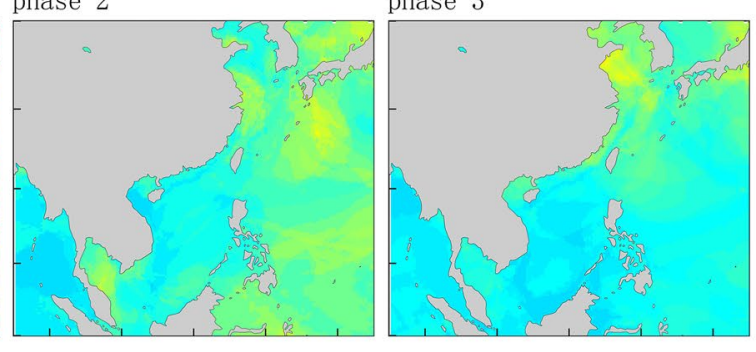

phase 4

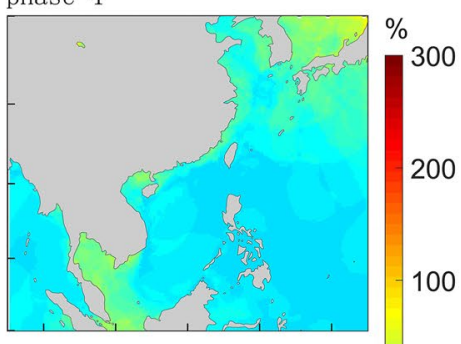

b)
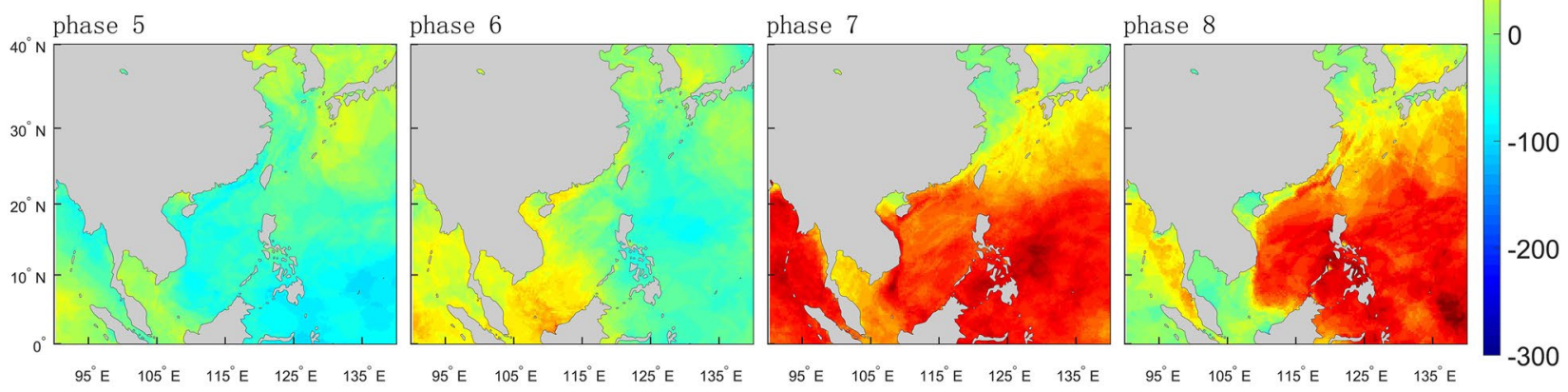

Figure 8. Probability changes of ESL events in MJO phases for DAC: extreme high events (R95) (a); extreme low events (R5) (b).

For the probability of DAC extremes, the strength of suppressing effect of MJO is usually weaker than that of the encouraging effect, either in ESL high or ESL low. The same results are found in the probability of SLA extremes (Figure S8). This is related in part to the definition of $\Delta P_{I S O_{i}}$ in Equation 1. In Equation 1, the ideal minimum percentage is $-100 \%$, while the maximum value is $1900 \%$. This means that the values of $\Delta P_{I S O_{i}}$ are not equally distributed around 0 . Another point worth noticing is that the MJO effect on the probability of ESL high is stronger than the effect on the probability of ESL low (phases 3-4 in Figure 8a and phases 7-8 in Figure 8b). This might be related to the fact that in the convective regions MJO has a more profound impact on the low-pressure systems (e.g., tropical cyclones and equatorial waves) (e.g., Bessafi \& Wheeler, 2006; Ho et al., 2006; Klotzbach \& Oliver, 2015). With appearance of low-pressure systems in MJO phases 3-5, due to convergent surface wind and low-pressure, the chance of ESL high event is largely increased. The happening of ESL low event is more likely related to the high-pressure systems. In phases 7-1 when high-pressure is dominating in the WNP, the chance of ESL low event becomes high. During the 
a)

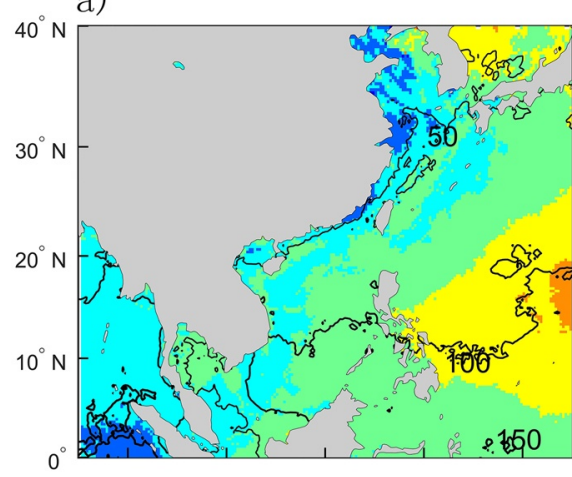

d)

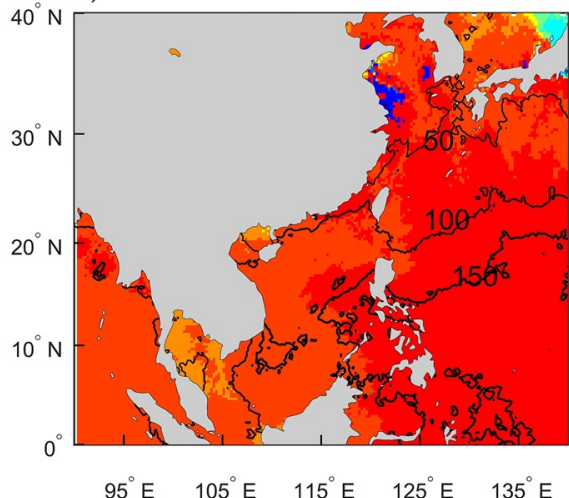

b)

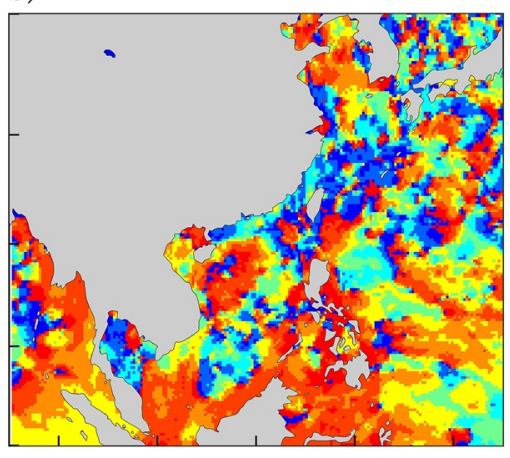

e)

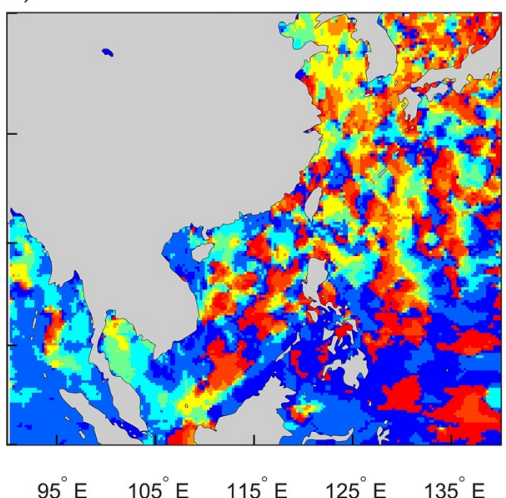

c)

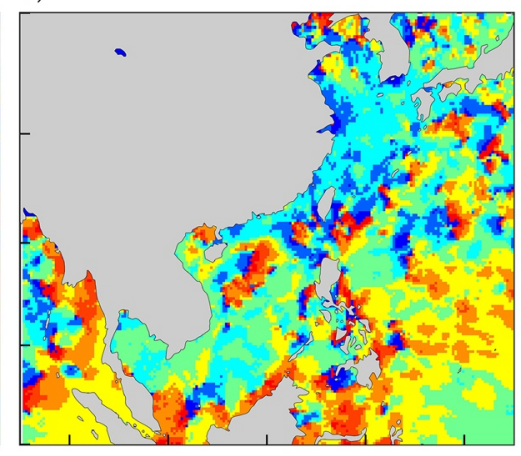

phase

8

7

6

5

f)

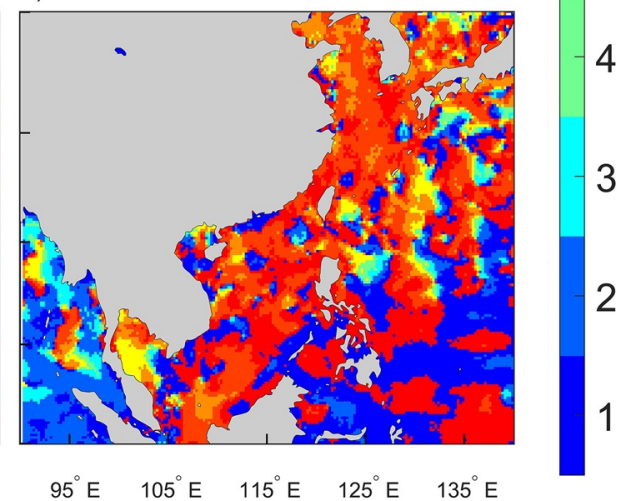

Figure 9. Harmonic parameters of probability changes in ESL high events due to MJO modulations for (a) DAC, (b) SLA, and (c) TSL, respectively. (d-f) as in $(\mathrm{a}-\mathrm{c})$, but for ESL low events. Colors indicate phase and contours represent amplitude (units: \%). The contours are drawn at $50 \%$ interval in amplitude.

eastward propagation of MJO, the difference between the amplitude of atmospheric anomalies in phases 7-1 and 3-5 leads to the difference of encouraging effect.

The relationships between MJO and SLA extremes are shown in Figures 9b and 9e. MJO tends to modulate the occurrence of ESL high from north to south and ESL low from south to north. However, this is not very conclusive, related to the small-scale features. For the occurrence of ESL high events of TSL (Figure 9c), in the north the highest probability occurs in MJO phases 2-3, while in the equatorial region the highest probability occurs in phases 4-5. In contrast, for the occurrence of ESL low events of TSL (Figure 9f), in the north the highest probability occurs in phases $6-7$, and in the equatorial region it occurs in phases 8-1.

\subsubsection{Summer}

The teleconnections from BSISO to summer ESL are shown in Figure 10. For ESL high events (R95) in summer DAC, BSISO alters its probability in most of the WNP. In BSISO phases 6-7, the probability of ESL high events is increased by $>300 \%$, relative to the reference probability for ESL, in the SCS and east of the Philippines $\left(10^{\circ} \mathrm{N}-30^{\circ} \mathrm{N}\right)$. In contrast, in BSISO phases $2-3$, the increased probability is lower in these regions for ESL low (R5) events in DAC, in the range of $200 \%-300 \%$.

There are two points worth further noticing. The first point is that in BSISO phases 1 and 5, the effect of BSISO on ESL events is out of phase in the tropical and subtropical regions (Figure 10). This is related to the two anomalous wind circulations at the surface (Figure 6). In BSISO Phase 1, an anti-cyclonic system is in the tropics and a cyclonic system in the subtropics. Conversely, in Phase 5, the cyclonic circulation appears in the tropics and the anti-cyclonic circulation moves to the subtropics. And the second one is that the encouraging effects of BSISO on the probability of ESL high are stronger than that of ESL low (phases 6-8 in Figure 10a and phases 2-4 in Figure 10b). The non-antisymmetric effects of BSISO are related to the stronger cyclonic circulation in phases 6-8 and the weaker anti-cyclonic circulation in phases 2-4 (Figure 6). 

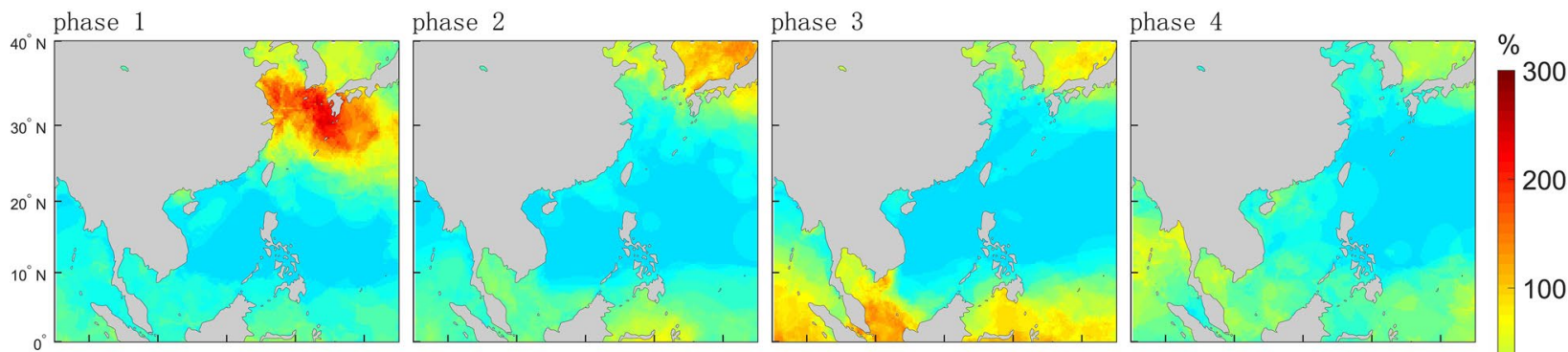

a)
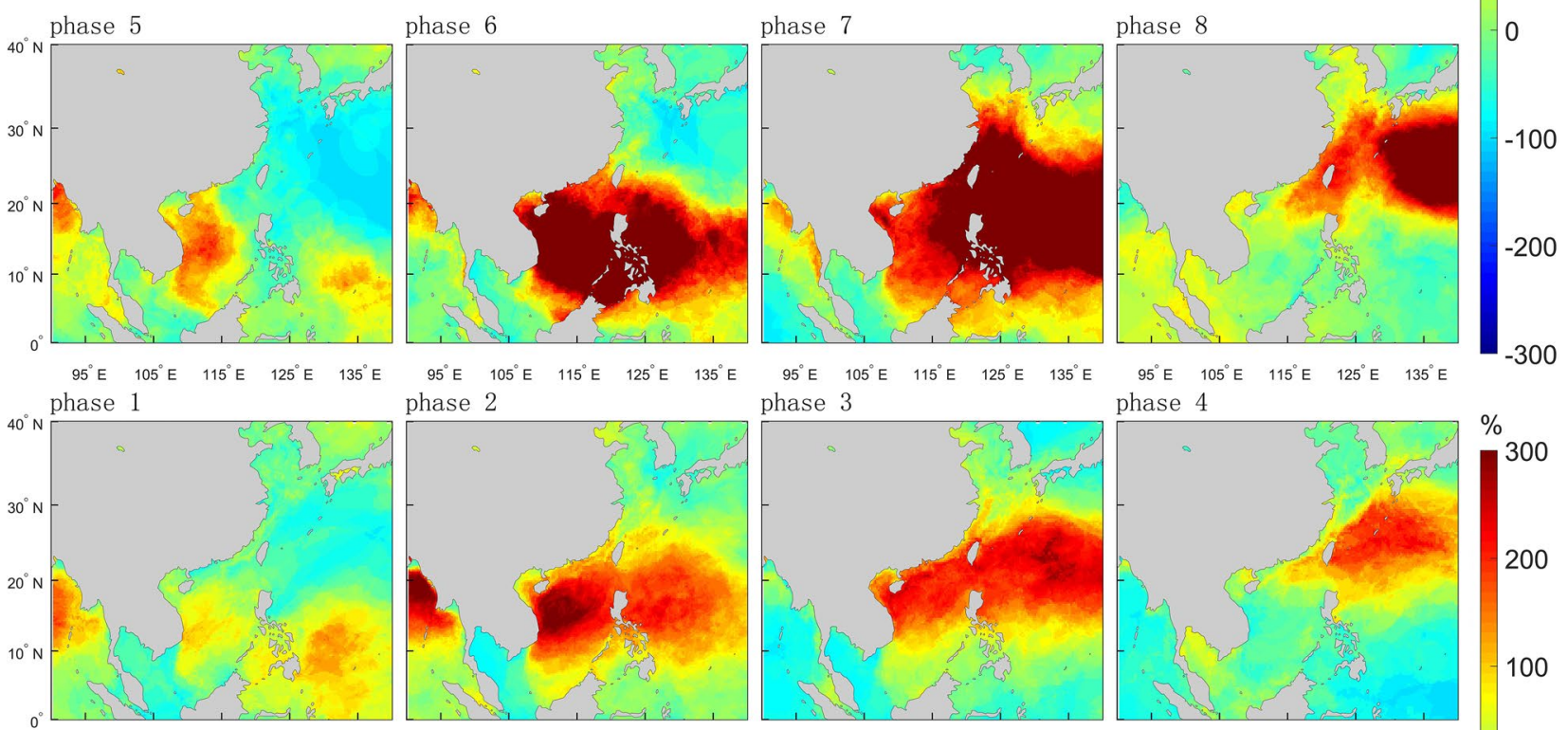

phase 2

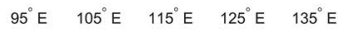

$95^{\circ} \mathrm{E} \quad 105^{\circ} \mathrm{E} \quad 115^{\circ} \mathrm{E} \quad 125^{\circ} \mathrm{E} \quad 135^{\circ} \mathrm{E}$
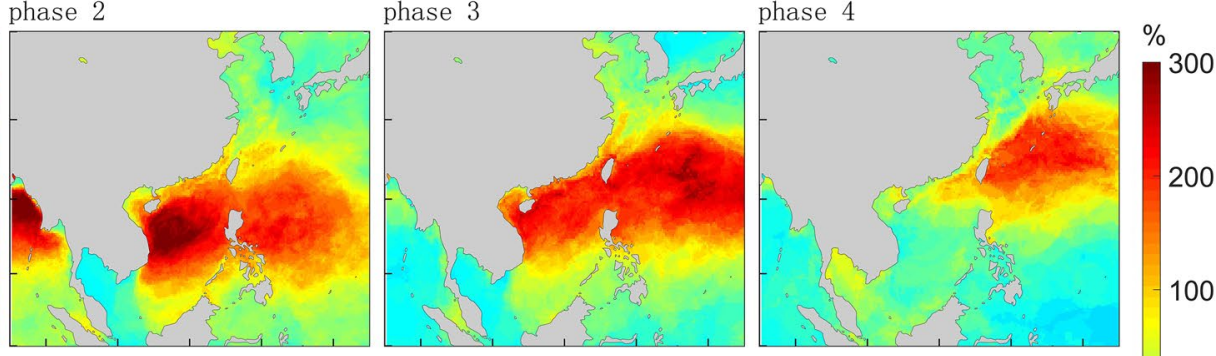

b)
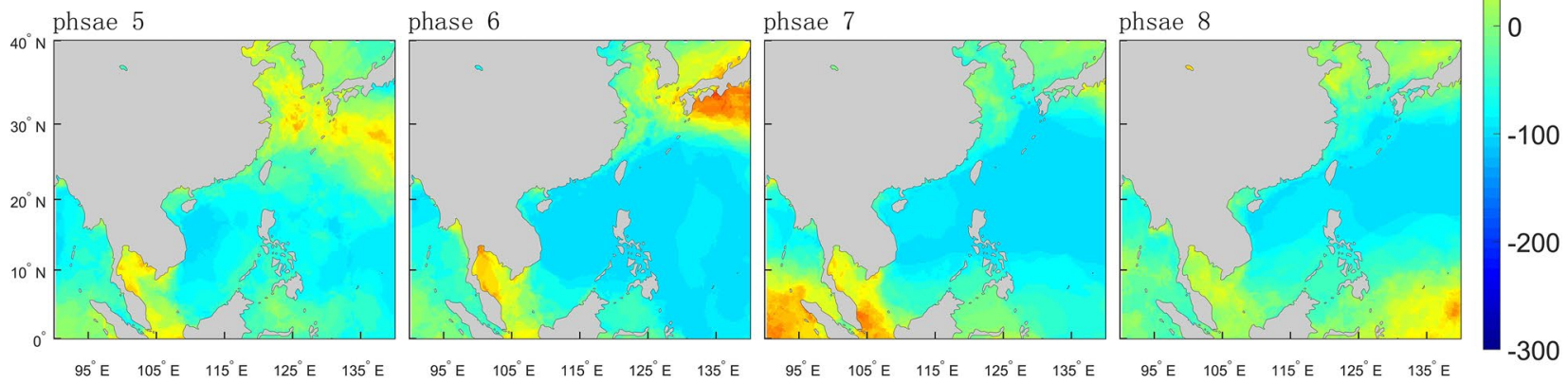

Figure 10. As in Figure 8, but for BSISO and in summer season.

The timing of the highest probability changes of ESL regressed to BSISO lifecycle is shown in Figure 11, with values passing the significance test provided in Figure S9. In the tropics $\left(0^{\circ} \mathrm{N}-10^{\circ} \mathrm{N}\right)$, ESL high events of DAC are most likely to happen in BSISO phases 3 and 6, with an increase of $50 \%-200 \%$ in the probability; in the subtropics $\left(10^{\circ} \mathrm{N}-30^{\circ} \mathrm{N}\right)$, they are most likely to happen in BSISO phases $6-8$, with an increase of $200 \%-250 \%$ in the probability. For ESL low events, in the tropics, the probability increases by $50 \%-150 \%$ in BSISO phases 1-2, while in the subtropics their probability increases by $100 \%-200 \%$ in BSISO phases 3-4. Again, the occurrence of extremes in SLA is not conclusively modulated by BSISO. The occurrence of ESL events for TSL has a relationship with BSISO that is similar to DAC. 
a)

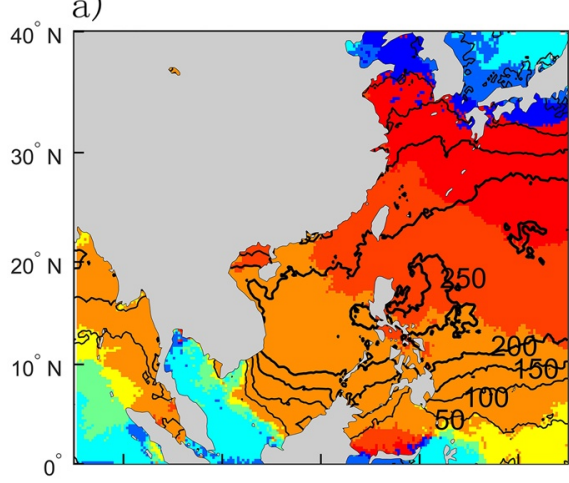

d)

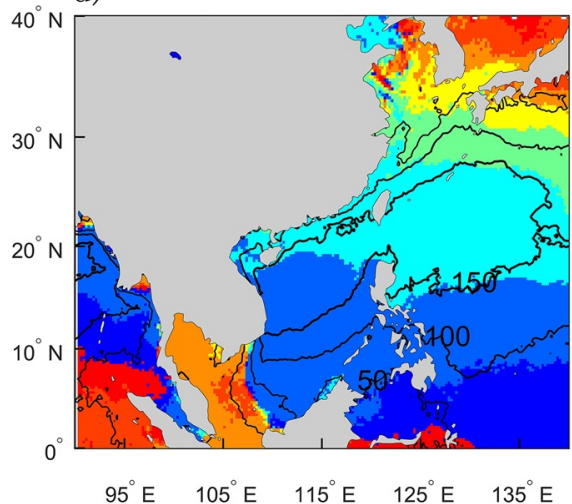

b)

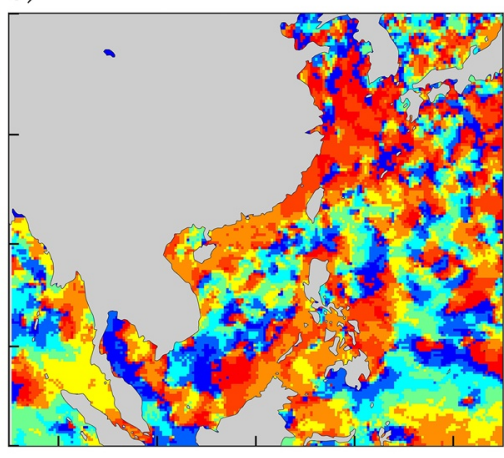

e)

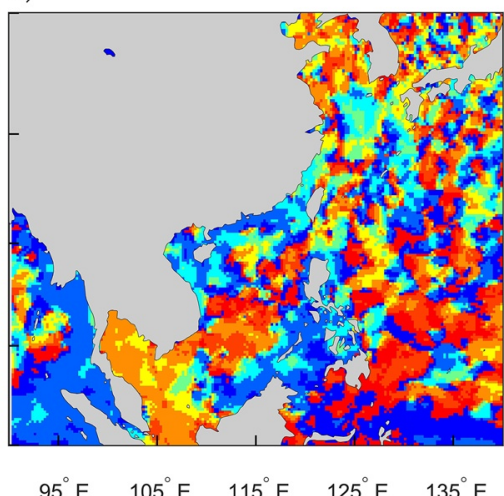

c)

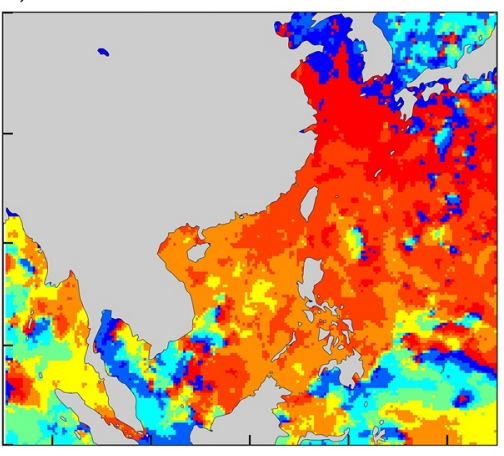

phase

8

7

6

5

f)

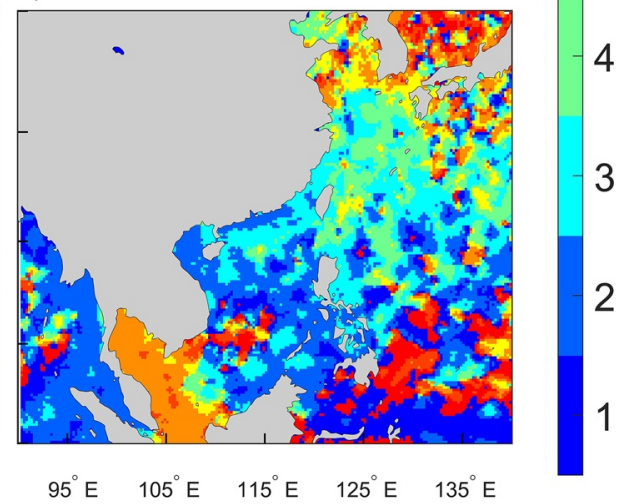

Figure 11. As in Figure 9, but for BSISO and in summer season.

\section{Conclusions and Discussion}

In this study, we investigated the intraseasonal variability of daily sea levels in the WNP by using 25 years (1993-2017) of satellite altimetry data for sea level anomaly (SLA) and the barotropic model output (DAC) for sea level forced by the high-frequency atmospheric forcing. The relationships between the ISO of the atmosphere (MJO and BSISO) and sea levels were examined.

Our analysis suggested that the atmospheric ISO significantly affects the composite anomaly of DAC in the vast majority of the WNP. During boreal winter (DJF), with the atmospheric convection related to MJO propagating to east, there is an apparent eastward propagation of DAC anomalies, in the range of $2-3 \mathrm{~cm}$. In MJO phases 2-3, positive DAC anomalies appear in the western marginal seas, with the largest values of $2-3 \mathrm{~cm}$ in the Taiwan Strait. Significant negative anomalies are found in these regions in MJO phases 7-8 (Figure 2a). In summer (JJA), the northeastward propagation of two large-scale wind circulations associated with BSISO leads to the southwest-northeast movement of DAC anomalies, in the range of 4-6 cm. The largest effects of BSISO are found east of Taiwan, with negative anomalies in BSISO phases 3-4 and positive anomalies in phases 7-8 (Figure 5a). The variability of DAC is the result of MSLP and surface wind. We further confirmed that MSLP plays a dominant role in the open ocean for ISO associated variability of DAC, while surface wind makes a significant contribution mostly in the coastal regions, such as the Taiwan Strait.

MJO-related SLA in winter has an amplitude of $2-6 \mathrm{~cm}$ in the WNP, with the larger values in the tropics. In MJO phases 5-6, the largest positive SLA values are found in the Andaman Sea and Malaysia Strait and east of the Philippines, whereas negative values of SLA are found in the subtropics (Figure 2b). Conversely, in MJO phases 1-2, the largest positive SLA anomalies appear in the regions of the subtropics such as the East China Sea and Sea of Japan, when comprehensive negative SLA anomalies are found in the tropics. In summer, the largest values of BSISO-associated SLA are found in the coastal regions and east of the Philippines, in the range of 2-6 cm. In BSISO phases 2-3, negative SLA values are in the subtropics and positive values in 
the tropics (Figure 5b). In contrast, in BSISO phases 6-7, positive SLA values are presented in the subtropics and negative values are in the tropics. The MJO-SLA and BSISO-SLA relationships can be interpreted by the geostrophic currents and convergence (divergence) of seawater driven by the surface wind circulations on intraseasonal timescales.

We also evaluated the effect of MJO and BSISO on the probability of extreme sea level (ESL) events. The most robust effect was found in DAC. In winter, the probability of ESL high events increases by $100 \%-200 \%$ from the western coasts to the central tropics, allocated to MJO phases 2-3 and 4-5, respectively (Figure 8a). This is likely related to the dominating low-pressure weather systems, which are responsible for ESL high events. In MJO phases 7-8, the chance of ESL low events in the tropics increases by $200 \%-300 \%$ (Figure 8b). Similarly, this could be attributed to the MJO effects on the distribution of the high-pressure weather systems. In summer, BSISO can largely alter the probability of ESL events. In the SCS and east of the Philippines, in BSISO phases 6-7, the probability of ESL high increases by $>300 \%$ (Figure 9a); in phases $2-3$, the chance of ESL low events increases by $200 \%-300 \%$ (Figure 9b). This could be related to the stronger cyclonic wind circulation in phases 6-7 and the weaker anti-cyclonic wind circulation in phases 2-3.

The effect by long-time climate variability is not included in this study. A caveat in this study is that the robustness of our results based on the unconditional composite analysis may be altered once the effect by long-time climate variability is considered. The atmospheric ISO could change with long-time climate variability, including the El Niño Southern Oscillation (ENSO) and the Pacific Decadal Oscillation (PDO). For example, the MJO intensity in warm phases of ENSO is weaker than in the cold phases (Chen et al., 2016; Li \& Zhou, 1994; Pang et al., 2016). The compound effects of ISO and other climate variability on the WNP sea level, e.g., conditional on different combinations of climate variability, will be investigated in our future work.

Our analysis implies the potential for developing a dynamical-statistical hybrid approach to predict sea level variations (including the ESL events) in the WNP on intraseasonal timescales, given the fact that some of existing dynamical climate models can skillfully predict the MJO and BSISO a few weeks ahead (e.g., Hudson et al., 2013; S.-S. Lee et al., 2015; H.-L. Ren et al., 2017; W. Wang et al., 2014). In the future, it will be worth evaluating the performance of the hybrid predictions against the traditional dynamical predictions for sea level intraseasonal variability.

\section{Data Availability Statement}

The DAC data are distributed by the Archiving, Validation and Interpretation of Satellite Oceanographic data program (AVISO), with support from CNES (http://www.aviso.altimetry.fr/duacs/). SLA daily gridded data were obtained from the Copernicus Climate Data Store (https://cds.climate.copernicus.eu/). MJO indices were obtained from the Bureau of Meteorology of Australian Government (http://www.bom.gov. $\mathrm{au} / \mathrm{climate} / \mathrm{mjo} /$ ). BSISO indices were obtained from the APEC Climate Center of the Korea Meteorological Administration (https://apcc21.org/ser/moni.do?lang=en). 10m height wind speed and mean sea level pressure data were obtained from the European Center for Medium-Range Weather Forecasts (https://apps. ecmwf.int/datasets/data/interim-full-daily/levtype=sfc/).

Acknowledgments

This work was supported by the foundation of the process and mechanism of interaction between shoal-channel evolution and river-tide dynamics in the Yangtze River estuary (Project No: U2040203), the National Key Research and Development Program of China (Project No: 2020YFD0900701), and the Belt and Road Special Foundation of the State Key Laboratory of Hydrology-Water Resources and Hydraulic Engineering, China (Project No: 2018490111). Xiangbo Feng was also supported by the Met Office Climate Science for Service Partnership for China and the Weather and Climate Science for Service Partnership for Southeast Asia, as part of the Newton Fund.

\section{References}

Anandh, P. C., \& Vissa, N. K. (2020). On the linkage between extreme rainfall and the Madden-Julian Oscillation over the Indian region. Meteorological Applications, 27(2), e1901. https://doi.org/10.1002/met.1901

Bessafi, M., \& Wheeler, M. C. (2006). Modulation of south Indian Ocean tropical cyclones by the Madden-Julian Oscillation and convectively coupled equatorial waves. Monthly Weather Review, 134(2), 638-656. https://doi.org/10.1175/MWR3087.1

Carrère, L., \& Lyard, F. (2003). Modeling the barotropic response of the global ocean to atmospheric wind and pressure forcing - Comparisons with observations. Geophysical Research Letters, 30(6). https://doi.org/10.1029/2002GL016473

Chen, X., Ling, J., \& Li, C. (2016). Evolution of the Madden-Julian Oscillation in two types of El Niño. Journal of Climate, 29(5), 1919-1934. https://doi.org/10.1175/JCLI-D-15-0486.1

Dee, D. P., Uppala, S. M., Simmons, A. J., Berrisford, P., Poli, P., Kobayashi, S., et al. (2011). The ERA-Interim reanalysis: Configuration and performance of the data assimilation system. Quarterly Journal of The Royal Meteorological Society, 137(656), 553-597. https://doi. org/10.1002/qj.828

Fang, G., Fang, W., Fang, Y., \& Wang, K. (1998). A survey of studies on the South China Sea upper ocean circulation. Acta Oceanographica Taiwanica, 37(1), 1-16. 
Feng, X., Haines, K., \& de Boisséson, E. (2018a). Coupling of surface air and sea surface temperatures in the CERA-20C reanalysis. Quarterly Journal of the Royal Meteorological Society, 144(710), 195-207. https://doi.org/10.1002/qj.3194

Feng, X., Haines, K., Liu, C., Boisséson, E., \& Polo, I. (2018b). Improved SST-precipitation intraseasonal relationships in the ECMWF coupled climate reanalysis. Geophysical Research Letters, 45(8), 3664-3672. https://doi.org/10.1029/2018GL077138

Feng, X., \& Tsimplis, M. N. (2014). Sea level extremes at the coasts of China. Journal of Geophysical Research: Oceans, $119(3), 1593-1608$. https://doi.org/10.1002/2013JC009607

Feng, X., Tsimplis, M. N., Marcos, M., Calafat, F. M., Zheng, J., Jordà, G., \& Cipollini, P. (2015a). Spatial and temporal variations of the seasonal sea level cycle in the northwest Pacific. Journal of Geophysical Research: Oceans, 120(10), 7091-7112. https://doi. org/10.1002/2015JC011154

Feng, X., Tsimplis, M. N., \& Woodworth, P. L. (2015b). Nodal variations and long-term changes in the main tides on the coasts of China. Journal of Geophysical Research: Oceans, 120(2), 1215-1232. https://doi.org/10.1002/2014JC010312

Feng, X., Zheng, J., \& Yan, Y. (2012). Wave spectra assimilation in typhoon wave modeling for the East China Sea. Coastal Engineering, 69, 29-41. https://doi.org/10.1016/j.coastaleng.2012.05.007

Hall, J. D., Matthews, A. J., \& Karoly, D. J. (2001). The modulation of tropical cyclone activity in the Australian region by the Madden-Julian Oscillation. Monthly Weather Review, 129(12), 2970-2982. https://doi.org/10.1175/1520-0493(2001)129<2970:TMOTCA>2.0.CO;2

Han, W., Lawrence, D. M., \& Webster, P. J. (2001). Dynamical response of equatorial Indian Ocean to intraseasonal winds: Zonal flow. Geophysical Research Letters, 28(22), 4215-4218. https://doi.org/10.1029/2001GL013701

Hartmann, D. L., Michelsen, M. L., \& Klein, S. A. (1992). Seasonal variations of tropical intraseasonal oscillations: A 20-25-day oscillation in the western Pacific. Journal of the Atmospheric Sciences, 49(14), 1277-1289. https://doi.org/10.1175/1520-0469(1992)049<1277 :SVOTIO $>2.0 . \mathrm{CO} ; 2$

Ho, C.-H., Kim, J.-H., Jeong, J.-H., Kim, H.-S., \& Chen, D. (2006). Variation of tropical cyclone activity in the South Indian Ocean: El Niño-Southern Oscillation and Madden-Julian Oscillation effects. Journal of Geophysical Research, 111(D22). https://doi. org/10.1029/2006JD007289

Hsu, P.-C., Lee, J.-Y., Ha, K.-J., \& Tsou, C.-H. (2017). Influences of boreal summer intraseasonal oscillation on heat waves in monsoon Asia. Journal of Climate, 30(18), 7191-7211. https://doi.org/10.1175/JCLI-D-16-0505.1

Huang, Z., Zhang, W., Geng, X., \& Hsu, P.-C. (2020). Accumulated effect of intra-seasonal oscillation convections over the tropical Western North Pacific on the meridional location of western Pacific subtropical high. Frontiers of Earth Science, 8, 630. https://doi.org/10.3389/ feart.2020.579442

Hudson, D., Marshall, A. G., Yin, Y., Alves, O., \& Hendon, H. H. (2013). Improving intraseasonal prediction with a new ensemble generation strategy. Monthly Weather Review, 141(12), 4429-4449. https://doi.org/10.1175/MWR-D-13-00059.1

Iskandar, I., Mardiansyah, W., Masumoto, Y., \& Yamagata, T. (2005). Intraseasonal Kelvin waves along the southern coast of Sumatra and Java. Journal of Geophysical Research, 110(C4). https://doi.org/10.1029/2004JC002508

Kikuchi, K., Wang, B., \& Kajikawa, Y. (2012). Bimodal representation of the tropical intraseasonal oscillation. Climate Dynamics, 38(9-10), 1989-2000. https://doi.org/10.1007/s00382-011-1159-1

Klotzbach, P. J., \& Oliver, E. C. J. (2015). Modulation of Atlantic basin tropical cyclone activity by the Madden-Julian Oscillation (MJO) from 1905 to 2011. Journal of Climate, 28(1), 204-217. https://doi.org/10.1175/JCLI-D-14-00509.1

Lee, J.-Y., Wang, B., Wheeler, M. C., Fu, X., Waliser, D. E., \& Kang, I.-S. (2013). Real-time multivariate indices for the boreal summer intraseasonal oscillation over the Asian summer monsoon region. Climate Dynamics, 40(1-2), 493-509. https://doi.org/10.1007/ s00382-012-1544-4

Lee, S.-S., Wang, B., Waliser, D. E., Neena, J. M., \& Lee, J.-Y. (2015). Predictability and prediction skill of the boreal summer intraseasonal oscillation in the intraseasonal variability hindcast experiment. Climate Dynamics, 45(7), 2123-2135. https://doi.org/10.1007/ s00382-014-2461-5

Li, C. Y., \& Zhou, Y. P. (1994). Relationship between intraseasonal oscillation in the tropical atmosphere and ENSO. Chinese Journal of Geophysics, 37(1), 17-26.(in Chinese).

Madden, R. A. (1986). Seasonal variations of the 40-50 day oscillation in the tropics. Journal of the Atmospheric Sciences, 43(24), 31383158. https://doi.org/10.1175/1520-0469(1986)043<3138:SVOTDO >2.0.CO;2

Madden, R. A., \& Julian, P. R. (1971). Detection of a 40-50 day oscillation in the zonal wind in the tropical Pacific. Journal of the Atmospheric Sciences, 28(5), 702-708. https://doi.org/10.1175/1520-0469(1971)028<0702:DOADOI >2.0.CO;2

Madden, R. A., \& Julian, P. R. (1972). Description of global-scale circulation cells in the tropics with a 40-50 day period. Journal of the Atmospheric Sciences, 29(6), 1109-1123. https://doi.org/10.1175/1520-0469(1972)029<1109:DOGSCC>2.0.CO;2

Maloney, E. D., \& Hartmann, D. L. (2000a). Modulation of eastern north Pacific hurricanes by the Madden-Julian Oscillation. Journal of Climate, 13(9), 1451-1460. https://doi.org/10.1175/1520-0442(2000)013<1451:MOENPH>2.0.CO;2

Maloney, E. D., \& Hartmann, D. L. (2000b). Modulation of hurricane activity in the Gulf of Mexico by the Madden-Julian Oscillation. Science, 287(5460), 2002-2004. https://doi.org/10.1126/science.287.5460.2002

Marcos, M., Tsimplis, M. N., \& Calafat, F. M. (2012). Inter-annual and decadal sea level variations in the north-western Pacific marginal seas. Progress in Oceanography, 105, 4-21. https://doi.org/10.1016/j.pocean.2012.04.010

Nagura, M., \& McPhaden, M. J. (2012). The dynamics of wind-driven intraseasonal variability in the equatorial Indian Ocean. Journal of Geophysical Research, 117(C2). https://doi.org/10.1029/2011JC007405

Oliver, E. C. J. (2014). Intraseasonal variability of sea level and circulation in the Gulf of Thailand: The role of the Madden-Julian Oscillation. Climate Dynamics, 42(1-2), 401-416. https://doi.org/10.1007/s00382-012-1595-6

Oliver, E. C. J., \& Thompson, K. R. (2010). Madden-Julian Oscillation and sea level: Local and remote forcing. Journal of Geophysical Research, 115(C1). https://doi.org/10.1029/2009JC005337

Oliver, E. C. J., \& Thompson, K. R. (2011). Sea level and circulation variability of the Gulf of Carpentaria: Influence of the Madden-Julian Oscillation and the adjacent deep ocean. Journal of Geophysical Research, 116(C2). https://doi.org/10.1029/2010JC006596

Pang, B., Chen, Z., Wen, Z., \& Lu, R. (2016). Impacts of two types of El Niño on the MJO during boreal winter. Advances in Atmospheric Sciences, 33(8), 979-986. https://doi.org/10.1007/s00376-016-5272-2

Pascual, A., Marcos, M., \& Gomis, D. (2008). Comparing the sea level response to pressure and wind forcing of two barotropic models: Validation with tide gauge and altimetry data. Journal of Geophysical Research, 113(C7). https://doi.org/10.1029/2007JC004459

Ponte, R. M. (2006). Low-frequency sea level variability and the inverted barometer effect. Journal of Atmospheric and Oceanic Technology, 23(4), 619-629. https://doi.org/10.1175/JTECH1864.1

Rajendran, K., \& Kitoh, A. (2006). Modulation of tropical intraseasonal oscillations by ocean-atmosphere coupling. Journal of Climate, 19(3), 366-391. https://doi.org/10.1175/JCLI3638.1 
Ren, H.-L., Jin, F.-F., Song, L., Lu, B., Tian, B., Zuo, J., et al. (2017). Prediction of primary climate variability modes at the Beijing Climate Center. Journal of Meteorological Research, 31(1), 204-223. https://doi.org/10.1007/s13351-017-6097-3

Ren, P., Ren, H. L., Fu, J. X., Wu, J., \& Du, L. (2018). Impact of boreal summer intraseasonal oscillation on rainfall extremes in southeastern China and its predictability in CFSv2. Journal of Geophysical Research: Atmospheres, 123(9), 4423-4442. https://doi. org/10.1029/2017JD028043

Roxy, M., \& Tanimoto, Y. (2012). Influence of sea surface temperature on the intraseasonal variability of the South China Sea summer monsoon. Climate Dynamics, 39(5), 1209-1218. https://doi.org/10.1007/s00382-011-1118-x

Shinoda, T., Hendon, H. H., \& Glick, J. (1998). Intraseasonal variability of surface fluxes and sea surface temperature in the tropical western Pacific and Indian Oceans. Journal of Climate, 11(7), 1685-1702. https://doi.org/10.1175/1520-0442(1998)011<1685:IVOSFA>2.0.CO;2

Sobel, A. H., Maloney, E. D., Bellon, G., \& Frierson, D. M. (2008). The role of surface heat fluxes in tropical intraseasonal oscillations. Nature Geosciences, 1(10), 653-657. https://doi.org/10.1038/ngeo312

Wang, B., \& Rui, H. (1989). Dynamics of the coupled moist Kelvin-Rossby wave on an equatorial $\beta$-plane. Journal of the Atmospheric Sciences, 47(4), 397-413. https://doi.org/10.1175/1520-0469(1990)047<0397:DOTCMK>2.0.CO;2

Wang, B., \& Xie, X. (1997). A model for the boreal summer intraseasonal oscillation. Journal of the Atmospheric Sciences, 54(1), 72-86. https://doi.org/10.1175/1520-0469(1997)054<0072:AMFTBS>2.0.CO;2

Wang, T., Yang, X.-Q., Fang, J., Sun, X., \& Ren, X. (2018). Role of air-sea interaction in the 30-60-day boreal summer intraseasonal oscillation over the Western North Pacific. Journal of Climate, 31(4), 1653-1680. https://doi.org/10.1175/JCLI-D-17-0109.1

Wang, W., Hung, M.-P., Weaver, S. J., Kumar, A., \& Fu, X. (2014). MJO prediction in the NCEP Climate Forecast System version 2. Climate Dynamics, 42(9), 2509-2520. https://doi.org/10.1007/s00382-013-1806-9

Wheeler, M. C., \& Hendon, H. H. (2004). An all-season real-time multivariate MJO index: Development of an index for monitoring and prediction. Monthly Weather Review, 132(8), 1917-1932. https://doi.org/10.1175/1520-0493(2004)132<1917:AARMMI>2.0.CO;2

Woolnough, S. J., Slingo, J. M., \& Hoskins, B. J. (2000). The relationship between convection and sea surface temperature on intraseasonal timescales. Journal of Climate, 13(12), 2086-2104. https://doi.org/10.1175/1520-0442(2000)013<2086:TRBCAS>2.0.CO;2

Wunsch, C., \& Stammer, D. (1997). Atmospheric loading and the oceanic "inverted barometer" effect. Reviews of Geophysics, 35(1), 79-107. https://doi.org/10.1029/96RG03037

Xavier, P., Rahmat, R., Cheong, W. K., \& Wallace, E. (2014). Influence of Madden-Julian Oscillation on southeast Asia rainfall extremes: Observations and predictability. Geophysical Research Letters, 41(12), 4406-4412. https://doi.org/10.1002/2014GL060241

Zhang, C. (2005). Madden-Julian Oscillation. Reviews of Geophysics, 43(2). https://doi.org/10.1029/2004RG000158 